\title{
Micronutrient Vitamin Deficiencies and Cardiovascular Disease Risk: Advancing Current Understanding
}

\author{
Christopher Edet Ekpenyong \\ Department of Physiology, Faculty of Basic Medical Sciences, University of Uyo, Uyo, Nigeria
}

Email address:

chrisvon300@yahoo.com, chrisvon200@yahoo.com

To cite this article:

Christopher Edet Ekpenyong. Micronutrient Vitamin Deficiencies and Cardiovascular Disease Risk: Advancing Current Understanding. European Journal of Preventive Medicine. Vol. 5, No. 1, 2016, pp. 1-18. doi: 10.11648/j.ejpm.20170501.11

Received: December 29, 2016; Accepted: January 20, 2017; Published: February 20, 2017

\begin{abstract}
Cardiovascular diseases are responsible for one-third of all deaths in the world. Several factors contribute to the current trend including micronutrient vitamin deficiencies (MVDs), however, opinions regarding the role of MVDs in CVDs are inconsistent; this could impact on micronutrient vitamins intake. The aim of this review was to provide a brief overview of published evidence on the associations between MVDs and CVDs, assess the interactions between micronutrients and cardiovascular endpoints, and identify current related research needs. Literature search conducted on studies published between 1963 and 2016 indicates that MVDs are common and are related to adverse cardiovascular endpoints through various mechanisms, including impaired antioxidant and immune response mechanisms; and anti-inflammatory activities. Some micronutrients directly impact on CVDs; others act as critical cofactors in several biochemical processes. Several methodologic flaws, environmental and individual susceptibility factors, lack of determination of baseline serum levels of complementary micronutrients, absence of uniformly accepted cut-off values, and interactions between micronutrients may partly account for discordant results across studies. Although MVD is a significant risk factor for CVDs, supplementation with single or paired micronutrients for primary prevention of CVDs in healthy adults with no special nutritional needs is discouraged; there is insufficient evidence to determine the benefit/harm of such supplementation.
\end{abstract}

Keywords: $\beta$-Carotene, Ascorbic Acid, Folate, Calciferol, Tocopherol, Deficiency, Heart Disease

\section{Introduction}

Micronutrient vitamin deficiencies (MVDs) are important public health issues due to the contributions to the pathogenesis, progression and mortality and morbidity burdens in many chronic diseases, including cardiovascular diseases (CVDs). CVDs are the major cause of morbidity and mortality globally, accounting for $>40 \%$ of total mortality [1] with increasing trends in developed and developing nations. It is posited that $>23$ million people are expected to be affected by CVDs by 2030 [2,3]. Although the use of drug treatment for conventional cardiovascular risk factors has been very effective, recent studies suggest failure to reach the optimal levels of treatment only in some patient groups [4]. This scenario underscores the need for improved prevention and treatment strategies for CVDs as the key action for achieving the best results. Health providers and nutritionists are actively seeking complementary methods, such as the use of diet (fruits and vegetables) rich in micronutrients and antioxidants to prevent and supplement treatment for CVDs [5]. However, it remains debatable whether MVDs cause CVDs, or whether micronutrient supplementation can postpone the onset of CVDs in those at risk or can mitigate progression and associated complications in those already affected [6]. Granted, there is much research interest on the relationship between MVDs and CVDs. Many studies [7, 8, 9, 10, 11, 12] have been conducted, and a number of trials are currently ongoing. New research findings regarding the function of some micronutrients in the body are being added to existing ones [13], which could provide additional data to identify the potential role of micronutrient supplementation in the primary and secondary prevention of CVDs [14].

Previous clinical trials of some micronutrients have shown significant correlations between deficiency states and cardiovascular risks/diseases [15, 16, 17], yet others showed the converse [18]. For instance, the Heart Outcome 
Prevention Evaluation trial, the Cambridge Heart Antioxidant study, the Norwegian Vitamin Trial, and the Western Norway B Vitamin Intervention trial [19, 20, 21] showed no clear evidence of benefits from $\mathrm{B}$ vitamin supplementation in terms of CVD risk reduction. These controversies have created confusion among the general public and may have impacted micronutrient intake, leading to fluctuating trends in micronutrient intake across the globe [22, 23, 24]. Nevertheless, the conflicting research findings could be resolved when one considers the effects of inadequately adjusted covariates, such as disparities in study design and methodologic flaws, including unreliable analytical methods $[25,26,27]$; variable doses [15]; the use of serum micronutrient measurements that may not adequately reflect long-term micronutrient intake [27, 28, 29, 30]; individual susceptibility factors; type and source of micronutrients; baseline micronutrient level [16], (e.g., very high or very low micronutrient at baseline); environmental factors; micronutrient interactions; inadequate pairing of micronutrients; and many other issues [31]. These have been shown to produce effects similar in magnitude to the observed health effect [14].

This review provides available evidence in favor of, and/or against the role of micronutrient vitamin deficiency (MVD) on cardiovascular endpoints, and extends the discussion on the pathophysiology and therapeutic implications of MVD in CVD.

\section{Methods}

A search using Medline, Scopus, and EMBASE databases was conducted to identify published articles within the period 1963-2016 using related terms such as micronutrients, essential nutrients, cardiovascular disease, vitamins, minerals, antioxidants, and anti-inflammatory and immunemodulatory micronutrients. For the purpose of this review, micronutrients were defined as vitamins, minerals, and trace elements essential for life. For each micronutrient, we considered evidence for or against its cardioprotective effects, its pharmacodynamics and pharmacokinetics, and current research needs.

All articles evaluating or reporting on the role of vitamins in cardiovascular disease and published within the study period, and met the inclusion criteria were included.

Articles with obvious methodology flaws (e.g., poor analytical methods) were excluded. If data were duplicated or shared in more than one study, the most recent, well presented and comprehensive study was included. In all, 210 articles (20 short communications, 60 review articles and 130 full research articles) were selected. However, 190 articles met the inclusion criteria and were included in the review.

Associations between vitamins and major cardiovascular events such as coronary artery disease, ischemic heart disease, myocardial infarction, angina and sudden cardiac death were explored.

Each article was evaluated for the type of study (e.g., primary, secondary or tertiary intervention trial), duration, and experimental dose of the tested vitamin.

Study design (double blind, randomized, randomized controlled trial, placebo controlled trial or open label), methodology quality (high or low) administrated supplement (single or in combination with other micronutrients) and duration of treatment. Only articles published in English were selected and evaluated.

\section{Pathophysiology of MVD-induced CVD}

Many reports [15-18] indicate that MVD is a significant risk factor for a wide spectrum of CVDs due to the ability to either initiate CVDs or worsen extant impaired cardiovascular function.

The pathophysiological mechanisms underlying MVDinduced CVDs include induction of imbalance in antioxidant defense mechanisms, inflammation and immune system dysfunction.

Central to these pathophysiolgic pathways is the induction of oxidative stress and subsequent generation of ROS, including peroxide, superoxide, and hydroxyl radicals. These free radicals have been implicated in a wide spectrum of CVDs due to the associated damage to endothelial cells; depletion of nitric oxide (NO), and oxidation of low-density lipoprotein-cholesterol (LDL-C).

Empirical evidences indicate that the micronutrient vitamin system mitigates the aforementioned three MVDinduced pathophysiologic processes leading to CVDs in three ways.

These include prevention of oxidant formation, inhibition of already formed oxidant and repairs to oxidant-induced cardiovascular injury, through their antioxidative, antiinflammatory and immune modulatory activities [32] (Tables 1,2 and 3 ).

Table 1. Vitamins with cardio-protective activities.

\begin{tabular}{l}
\hline Vitamins \\
\hline Vitamin A \\
Vitamin $\mathrm{B}_{1}$ \\
${\text { Vitamin } \mathrm{B}_{3}}_{\text {Vitamin }_{6}}$ \\
Vitamin $\mathrm{B}_{12}$ \\
Vitamin C \\
Vitamin D \\
Vitamin E \\
Vitamin K \\
Folic acid \\
\hline
\end{tabular}

Table 2. Vitamins and cardio-protective mode of actions.

\begin{tabular}{lll}
\hline Vitamins & & \\
\hline Antioxidants & Immune modulators & Anti-inflammatory \\
\hline Vitamin A & Vitamin A & Vitamin A \\
Vitamin C & Vitamin $\mathrm{B}_{6}$ & Vitamin $\mathrm{B}_{6}$ \\
Vitamin E & Folate $(\mathrm{B} 9)$ & Vitamin $\mathrm{B}_{12}$ \\
Nicotinamide & Vitamin $\mathrm{B}_{12}$ & Vitamin $\mathrm{E}$ \\
Riboflavin & Vitamin C & Folate $\left(\mathrm{B}_{9}\right)$ \\
Omega-3 fatty acid & Vitamin E & Vitamin C \\
- & Vitamin D & Vitamin D \\
\hline
\end{tabular}


Table 3. Classification of Vitamins based on the strength of their cardioprotective mode of action.

\begin{tabular}{llll}
\hline $\begin{array}{l}\text { Micronutrient } \\
\text { Vitamins }\end{array}$ & Antioxidants & $\begin{array}{l}\text { Immune } \\
\text { modulators }\end{array}$ & $\begin{array}{l}\text { Anti- } \\
\text { inflammatory }\end{array}$ \\
\hline Vitamin A & ++ & ++ & ++ \\
Vitamin $\mathrm{B}_{6}$ & + & ++ & ++ \\
Vitamin $_{9 \text { (Folate) }}$ & ++ & ++ & ++ \\
Vitamin $\mathrm{B}_{12}$ & - & ++ & ++ \\
Nicotinamide & ++ & - & - \\
Riboflavin $\left(\mathrm{B}_{2}\right)$ & ++ & - & - \\
Vitamin C & ++ & ++ & ++ \\
Vitamin D & + (indirect) & ++ & ++ \\
Vitamin E & ++ & ++ & ++ \\
\hline
\end{tabular}

++ : Persuasive evidence, typically from clinical trials.

+ : Suggestive evidence.

Central to these antioxidant pathways is the inhibition of LDL-C oxidation. Oxidized LDL-C initiates several biochemical and mechanical processes that lead to atherosclerosis. These include increase production of biologically active compounds, which impair the functional integrity of the vascular cells, and increase expression of endothelial cell surface molecules. There is also associated increase mobilization and uptake of circulating inflammatory cells, alteration of chemotactic property of monocytes and monocyte derived macrophages, increase intimal proliferation, fibrosis, calcification, plaque formation and plaque rupture leading to thrombus formation.

Oxidized LDL-C also inhibits NO synthesis due to its negative impact on vascular endothelial function. Low bioavailability of $\mathrm{NO}$ is associated with several processes that lead to atherosclerosis such as vasoconstriction, increase thrombocyte aggregation, monocyte migration to vascular wall, and increase formation of foam cells [33].

Alternatively, the associated inflammatory processes could lead to increase production of inflammatory cytokines such as interleukin (IL)-IB, IL-6, tumor necrosis factor-alpha (TNF- $\alpha$ ), and high sensitivity C-reactive protein and leading to endothelial dysfunction, atherosclerosis, vasoconstriction and CVDs. Furthermore, ROS can directly affect myocardial function through inhibition of the sarcoplasmic reticular calcium-pump in the cardiac cycle.

This action is associated with inactivation of troponin $\mathrm{C}$, changes in calcium balance, defect in systolic and diastolic function, decreased ventricular walls, changes in myocyte morphology (e.g., increase in length and size of myocyte, sarcomeric disorganization and myofibril disarray) [34, 35, $36]$ and leading to CVDs (Figure 1).

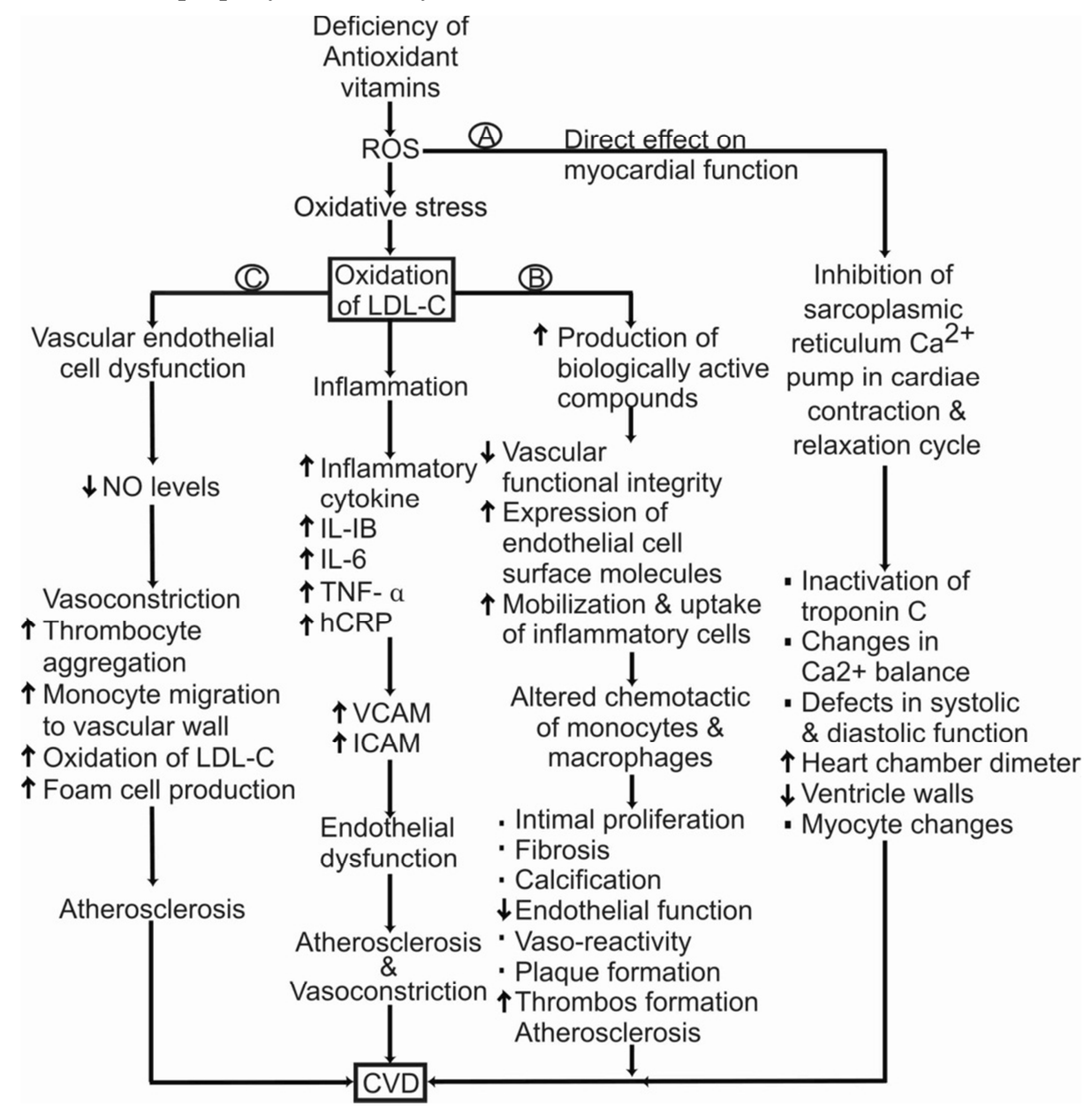

Figure 1. Oxidation of $L D L$ and pathogenesis of cardiovascular disease.

Schematic diagram showing three pathophysiologic pathways linking micronutrient deficiencies and cardiovascular diseases, including (A) direct effect on myocardial function, (B) increase production of biological active compounds, and (C) vascular endothelial cell dysfunction . 


\section{Specific Micronutrient Vitamin Deficiencies and CVD}

Although the causes of CVD often overlap, several experimental and clinical studies have yielded a significant amount of data suggesting that deficiencies in vitamins, minerals, and trace elements are major contributors to CVDs and CVD symptoms. To date, available literature suggests that MVDs can cause or worsen the risk factors for CVD [3]. In many of these studies, micronutrient vitamin (MNV) intake over an extended period was associated with decreased risk of cardiovascular events. Although this association has been challenged by some recent studies [37, 38], these studies have important limitations, including the effects of inadequately controlled covariates.

Adequate MNV intake is known to reduce the risk of hypertension and other cardiovascular risk factors. Studies evaluating the relationship between MVD and hypertension suggest MVD is more common in patients with hypertension and other CVDs than in the general population [31]. For instance, the link between deficiencies of vitamins A, C, D, and $\mathrm{E}$ and $\mathrm{CVD}$, including hypertension, has long been established. Vitamins A, C, and E constitute the nonenzymatic antioxidant vitamin barrier. Adequate plasma concentrations of these vitamins protects against ROS and, by extension, CVDs. Previous studies indicate lower levels of these vitamins in patients with CVDs [39, 40, 41, 42]. Similarly, deficiencies in several minerals and trace elements, such as calcium, magnesium, and chromium, have been linked to hypertension and other CVDs. A study by Chiplonkar et al. [43], conducted among 109 hypertensive adults and 115 age-sex-socioeconomic status-matched healthy, normotensive adults aged 30-58 years, showed that intake of some micronutrients (potassium, copper, folic acid, and vitamin C) was significantly lower in hypertensive than in normotensive subjects.

Similarly, a study conducted by the hypertension institute in Nashville found significantly lower levels of micronutrients in hypertensive than in normotensive patients. In that study, micronutrient replacement, in addition to other lifestyle modifications, controlled blood pressure in $62 \%$ of hypertensive subjects over a period of 6 months, even after discontinuation of antihypertensive drugs; nevertheless, unadjusted lifestyle factors could have confounded the results.

\subsection{Vitamin A ( $\beta$-Carotene) Deficiency and CVD}

Vitamin A is a fat soluble vitamin that exists as a provitamin ( $\beta$-carotene) in plants (roots, leaves, shoots, seed, fruits, and flowers). It is metabolized to retinoic acid. It also exists as a polyisopronoid compound (retinol) containing a cyclohexenyl ring in animals (eggs, poultry, and fish) (Figure 2A).

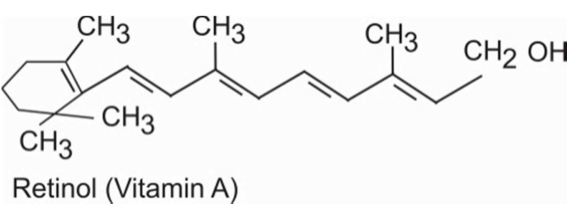

Figure 2A. Chemical structure of retinol (Vitamin A) containing a cyclohexenyl ring.

The double-bond in the carbon chain of the carotinoids may exist in different configurations, including trans and cis configurations (Figure 2B), giving rise to the different isomers of $\beta$-carotene.

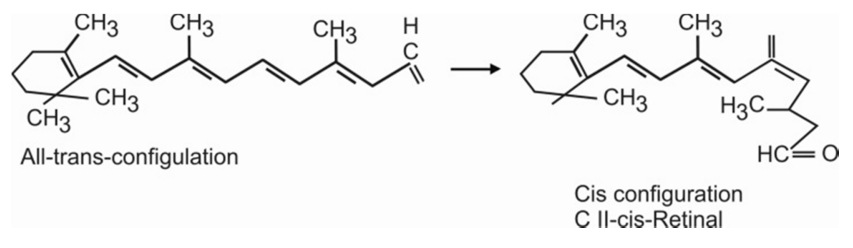

Figure 2B. Chemical structure of carotenoid compounds showing the trans and cis configurations.

Common isomers of $\beta$-carotene found in human plasma and foods include all-trans, 13-cis, and 15-cis isomers [45]. The form of $\beta$-carotene present in food is important because of the pharmacodynamic and pharmocokinetic bearings. The most common form in humans is the all-trans isomer [46] that is more stable than the cis form. Retinol is stored in the liver as retinol esters. It has two derivatives: retinal and retinoic acid. However, retinol is more potent and they are collectively known as retinoids. Retinoids and $\beta$-carotene function as anti-oxidants, anti-inflammatories, and immune modulators; hence, they protect the human body against various diseases, including CVDs. Over 500 plant-derived compounds constitute the carotinoids, however, the major ones include $\alpha$-carotene (collard greens, pumpkin, corn, yellow pepper, cloudberry), $\beta$-carotene (apricots, mangoes, red pepper, kale, spinach, broccoli, carrots), $\beta$-cryptoxanthin (orange, persimmon, avocado, pepper, passion fruit), lycopene (guava, watermelon, rose hip, tomato and tomato products, pink grape fruit), and lutein and xeaxanthin (corn, peas, spinach, collard greens, lettuce) $[1,47]$.

Data from most observational studies [48, 49, 50] found inverse associations between dietary intake or supplementation of vitamin A or $\beta$-carotene and CVD risk, including death from ischemic heart disease (IHD) and myocardial infarction (MI). However, several other studies found no association or increased risk of CVD. These studies include the large-scale, randomized double-blind, placebocontrolled trial of $\beta$-carotene (50 mg on alternate days) by Hennekens et al. [51], and the prospective, nested casecontrol study of male physicians without a prior history of CVD by Hak et al. [52]. Likewise, a study by Omenn et al. [53] in a high risk population of 18,314 smokers and former smokers found no association between $\beta$-carotene intake CVD risk.

Several factors have been postulated to account for these 
conflicting research results across studies, including individual susceptibility factors, treatment doses and duration, sources of $\beta$-carotene (dietary or supplementation), baseline plasma carotene level, and the presence of other nutrients in $\beta$-carotene-containing foods (including other carotenoid compounds) contributing to the observed cardioprotective effects. There is now considerable evidence that the experimental dose of $\beta$-carotene may impact its cardioprotective potential. Csepanyyi et al. [54] in their animal study found that at a lower dose $(30 \mathrm{mg} / \mathrm{kg} /$ day $)$ and short reperfusion times, $\beta$-carotene exhibited a significant cardioprotective effect, but that this protection was lost at higher doses $(150 \mathrm{mg} / \mathrm{kg} /$ day $)$ and higher reperfusion time. Lack of controlling for known physiologic and lifestyle factors, such as smoking, has also been implicated. Streat et al., [55], found that carotene deficiency was associated with a higher risk of subsequent $\mathrm{MI}$ in smokers but not in nonsmokers. Similarly, Hak et al. [52] showed no protective effect of different carotenoids against incident MI among smokers, but not among non-smokers. Some studies found cardioprotective effects only with dietary $\beta$-carotene but not with supplementation $[51,53]$, suggesting a complementary effect of other nutrients in $\beta$-carotene rich foods, including other caroteniods with cardioprotective potential, such as lutein [56]. Besides the carotenoids, other micronutrients present in plants can provide a polyvalent cardioprotective effect through different mechanisms. Hennekens et al. [51] reported a lack of improvement in patients with CVD and cancer treated with all-trans $\beta$-carotene, probably due to the absence of the complementary cardioprotective actions of other carotenoids. In a population study of 73,286 female nurses to assess the potential role of other dietary carotenoids in the prevention of coronary artery disease (CAD), Osganian et al. [47] found a moderate but significant inverse association between higher quintiles of intake of $\beta$-carotene and $\alpha$-carotene and the risk of CAD but not with other dietary carotenoids, suggesting that the type of dietary carotenoid affects its cardio-protective potential.

It has also been postulated that supplementation of vitamin A or $\beta$-carotene may not provide the desired cardio-protective effect in populations with relatively adequate baseline plasma levels, such as those with large intake of fruits and vegetables. Similarly, healthy individuals on a short-term carotene-deplete diet showed a significant improvement in biochemical markers of lipid peroxidation following supplementation with a $\beta$-carotene rich diet $[57,58]$. This observation suggests that supplementation of vitamin $A$ or $\beta$ carotene to individuals with adequate plasma levels at baseline may not produce any effect or may even be toxic to cells. Accordingly, the United States Preventive Services Task Force does not recommend $\beta$-carotene supplementation in healthy populations without known nutritional deficiencies as a means to reduce the risk of CVDs or cancer [59].

The underlying cardio-protective effect of vitamin $A$ or $\beta$ carotene is hypothesized to include attenuation of lipid oxidation, in particular, the oxidation of LDL-C in arteries; quenching of singlet oxygen [60]; and scavenging of free radicals. Furthermore, vitamin A (retinoic acid) exhibits potent anti-inflammatory and immune modulatory effects in atherosclerosis by inducing the formation regulatory T-cells (Tregs), CD4 T-cells that express fork head box protein 3 $\left(\mathrm{FOXP}^{3}\right)$. Tregs modulate immune and anti-inflammatory responses by suppressing $\mathrm{T}$-cell proliferation and the release anti-inflammatory cytokines including IL-10 and transforming growth factor (TGF)-1. These cytokines can inhibit inflammation and enhance atherosclerotic plaquestabilization. Results of a study by Mottaghi et al., [61] evaluating the effect of vitamin A supplementation on FOXP ${ }^{3}$ and TGF gene expression in atherosclerotic patients, showed that vitamin A supplementation caused increased $\mathrm{FOXP}^{3}$ and TGF expression in atherosclerotic patients, leading to increased anti-inflammatory and atherosclerotic plaquestabilizing effects of TGF. Conversely, deficiency of vitamin A was associated with a significant increase in serum hs-CRP [62], an independent predictor of adverse cardiovascular events [63]. CRP has been shown to worsen pre-existing tissue damage in a complement-dependent pattern [64]. This is in line with a study demonstrating that CRP enhances inflammation in ischemic myocardium by inducing local complement activation [65]; similar results were obtained by several other investigators [66, 67, 68]. In view of the obvious lack of evidence for benefit, supplementary use of $\beta$ carotene or vitamin A for primary prevention of CVD in healthy adults without special nutritional deficiency is not recommended.

\subsection{B-Vitamin (B-6, B-12 and Folate) Deficiencies and CVD}

$\mathrm{B}$-vitamins $\left(\mathrm{B}_{6}, \mathrm{~B}_{9}\right.$ and $\left.\mathrm{B}_{12}\right)$ function as cofactors in the metabolism of homocysteine. Homocysteine is a sulfurcontaining amino acid. It is an intermediate compound in the pathway of methionine metabolism to cysteine, and is normally recycled to maintain serum level at a physiologic limit (Figure 3A).

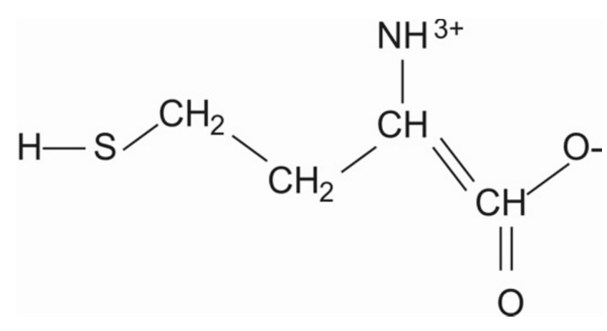

Figure 3A. Chemical structure of homocysteine.

Cysteine is an amino acid used for synthesis of glutathione, an important antioxidant. Normal serum levels of homocysteine are 5-15 $\mu \mathrm{mol} / \mathrm{L}$ [69]. Serum levels of homocysteine 15-29.99 $\mu \mathrm{mol} / \mathrm{L}, 30-99.99 \mu \mathrm{mol} / \mathrm{L}$, and $\geq$ $100 \mu \mathrm{mol} / \mathrm{L}$ are regarded as mild, moderate, and severe hyperhomocysteinemia, respectively [70, 71]. Two pathways (remethylation and transsulfuration) are involved in the metabolism of homocysteine to methionine and cysteine, respectively. Vitamins $\mathrm{B}_{6}, \mathrm{~B}_{9}$, and $\mathrm{B}_{12}$ function as cofactors in these pathways (Figure 3B). 


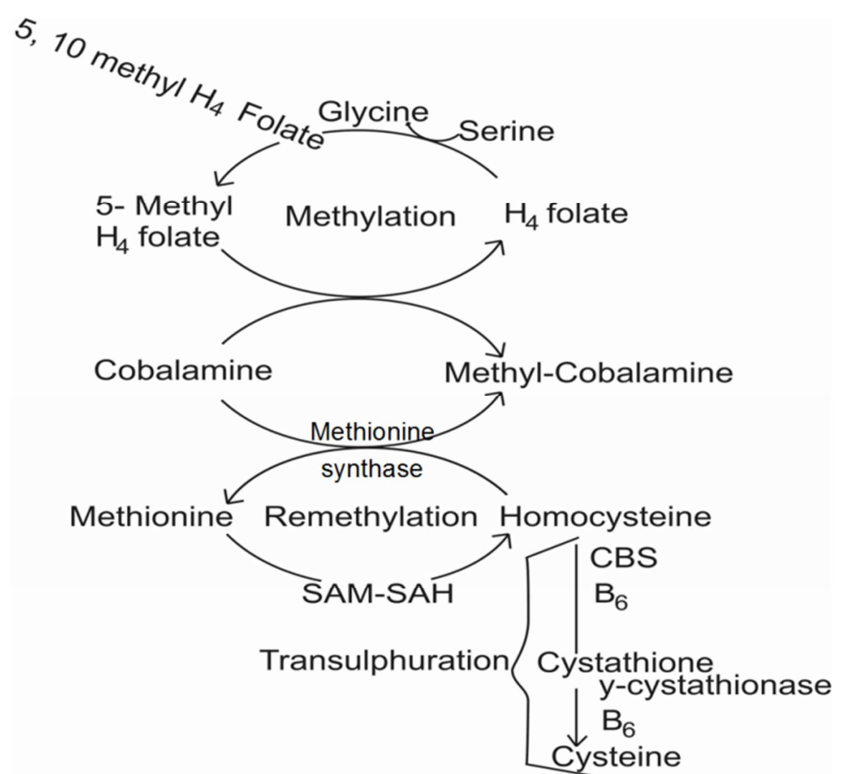

Figure 3B. Schematic illustration of the role of B-vitamins in the biosynthesis and metabolism of cysteine and homocysteine.
Deficiencies of these vitamins are associated with defective homocysteine metabolism leading to elevation in serum homocysteine levels (hyperhomocysteinemia). Numerous observational studies have investigated the relationship between $\mathrm{B}$-vitamins $\left(\mathrm{B}_{6}, \mathrm{~B}_{12}\right.$, and folate) and serum homocysteine level, and CVD risk. Data from these studies have shown that serum homocysteine level is inversely related to serum B-vitamins levels. B-vitamin insufficiencies have been shown to be associated with hyperhomocysteinemia in both sexes [72], and homocysteine levels have been shown to be directly related to CVD risk.

The pathophysiologic mechanisms underlying hyperhomocysteinemia-induced CVD have been postulated to include induction of endothelial damage and dysfunction, enhanced oxidation of LDL-C, smooth muscle proliferation, endothelial-leukocyte interactions, innate autoimmune disorders, inflammation, and oxidative stress [73]. There is enhanced atherosclerosis, cerebrovascular and peripheral disease, and other CVD events, including alteration of platelet function and coagulation factors leading to enhanced thrombogenesis [73, 74, 75, 76] (Figure 3C).

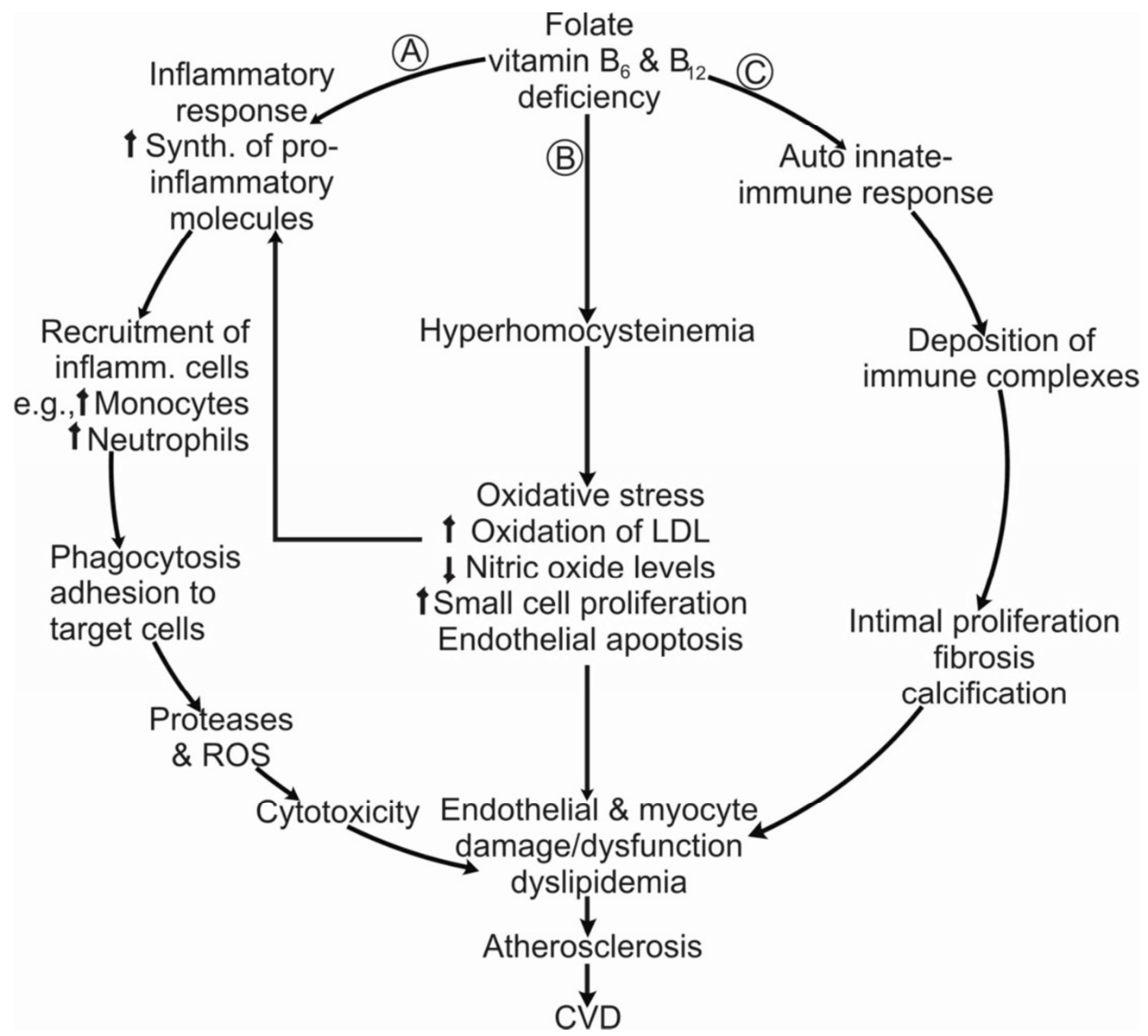

Figure 3C. Schematic illustration of the links between deficiency of the B-vitamins, hyperhomocysteinemia, and cardiovascular diseases.

A: Deficiency of B-vitamins can induce inflammatory responses leading to recruitment of inflammatory cells, phagocytosis, proteases, ROS, cytotoxicity, and endothelial damage.

B: Hyperhomocysteinemia promotes oxidative stress and causes oxidation of LDL-C by free radicals leading to vascular dysfunction including reduction in nitrous oxide levels, increased small cell proliferation, and endothelial apoptosis (Soyding et al. 2007).

C: B-vitamin deficiency can induce autoimmune dysfunction leading to deposition of immune complexes, dyslipidemia, atherosclerosis, and cardiovascular disease. 
Decreasing the plasma total homocysteine level by providing the cofactors for its metabolism (folic acid, vitamins $\mathrm{B}_{6}$, and $\mathrm{B}_{12}$ ) has been shown to reduce CVD risk $[77,78]$. In fact, it is proposed that for every $3 \mu \mathrm{mol} / \mathrm{L}$ decrease in serum homocysteine, there is a mean $16 \%$ reduction in CVD risk [79].

High levels of homocysteine are correlated with significant increase risk of CAD, MI [80], peripheral occlusive disease (deep vein thrombosis) [81, 82], and intermittent claudication [83]. According to Nygard et al. [84], a serum homocysteine level of $12 \%$ greater than the upper limit of normal is associated with a threefold increased risk of acute MI. Adequate plasma levels of folate and vitamins $B_{6}$ and $B_{12}$ significantly decreased mean serum levels of triglyceride and total cholesterol and simultaneously increased mean serum phospholipid and high density lipoprotein cholesterol (HDLC) levels [85], and vice versa.

In the Vitamin Intervention for Stroke Prevention study, Tool et al. [15] used high doses of B-vitamins (25 mg vitamin $\mathrm{B}, 400 \mu \mathrm{g}$ B-12, and $2500 \mu \mathrm{g}$ folic acid) to lower homocysteine levels in subjects with a previous history of stroke in order to prevent recurrent stroke, MI, and death. The high dose B-vitamins achieved a better cardioprotective effect than low dose or placebo. In a related study, Spence et al. [16] demonstrated a $21 \%$ reduction in the risk of stroke, CVD, or death in a high dose B-vitamin group. In the latter study, the exclusion criteria included very low or very high serum B-vitamin levels at baseline, and those already being treated with vitamin $B_{12}$. In the nurse health study of 80,082 women, an inverse association between the intake of vitamin $\mathrm{B}_{6}$ and folate and the risk of MI and cardiovascular death was reported [86]. Merchant et al. [87], in their study of 46,036 individuals aged $40-75$ years, reported a $21 \%$ lower rate of peripheral arterial disease for each $400 \mu \mathrm{mol} / \mathrm{L}$ increase in intake of B-vitamins. Cui et al. [88] made a similar observation in their study of 58,730 patients, assessing the effect of intake of folate, $\mathrm{B}_{6}$ and $\mathrm{B}_{12}$ on CVD endpoints.

However, several other studies found no association between vitamin $\mathrm{B}_{6}, \mathrm{~B}_{12}$, and folate and homocysteine level and CVDs, leading to the suggestion that the homocysteinelowering therapies of folic acid, vitamin $\mathrm{B}_{6}$, and vitamin $\mathrm{B}_{12}$ do not lower the risk of CVD; [69, 89, 90, 91, 92, 93]. For instance, in the Women's Antioxidant and Folic Acid Cardiovascular Study, daily supplementation with $2.5 \mathrm{mg}$ folate, $50 \mathrm{mg}$ vitamin $\mathrm{B}_{6}$, and $1 \mathrm{mg}$ of vitamin $\mathrm{B}_{12}$ for a mean of 7.3 years produced no effect on cardiovascular endpoints [94].

A study of 12,064 male survivors of MI treated with supplemental folic acid $(2 \mathrm{mg})$ and vitamin $\mathrm{B}_{12}(1 \mathrm{mg})$ for a mean period of 7 years demonstrated no major differences in the outcomes of MI, cardiovascular death, and stroke [95]. The Western Norway B-Vitamin Intervention Trial also produced lack of beneficial effect. Similar negative effect of B-vitamin supplementation was observed in an animal study by Omid et al. [96] that evaluated the impact of folate and vitamin $\mathrm{B}_{12}$ on cardiac function and morphology.
Given the mixed results reported in the aforementioned studies and in view of several methodologic flaws, caution should be exercised in drawing conclusions on the effect of these vitamins on CVD. A study on the role of vitamin $\mathrm{B}_{6}$ deficiency and serum homocysteine level and CVD indicated that besides impairing cysteine production and, hence, glutathione synthesis, hyperhomocysteinemia chelates copper and impairs copper-dependent enzyme activities, including superoxide dismutase (SOD), leading to increased lipid peroxidation [97]. Therefore, copper deficiency usually cooccurs with vitamin $\mathrm{B}_{2}$ or $\mathrm{B}_{6}$ or folate deficiency. This understanding led to the suggestion that copper deficiency plays a significant role in the pathogenesis of hyperhomocysteinemia-induced CVDs. Therefore, lowering serum level of homocysteine alone will not overcome the effect of coexisting copper deficiency on overall cardiovascular health. For instance, supplementation with B vitamins alone to ameliorate hyperhomocysteinemia-induced CVD will fail unless serum levels of copper remain within physiologic limits. This understanding may help to explain why supplementation of B-vitamins alone may fail to reverse hyperhomocysteinemia-induced CVD in some studies [89, 91], as these studies either failed to replace the associated copper deficiency or to ascertain the baseline serum level of copper. More studies are needed to determine at what baseline homocysteine level treatment will produce beneficial effects, in view of the negative results observed in individuals with normal homocysteine levels. In addition, the confounding effect of low level of serum copper should be adequately excluded.

Folate deficiency and CVD

An association between folate deficiency and coronary heart disease (CHD) has been established [79]. Available evidence suggests that $10-25 \%$ of deaths from CHD and stokes worldwide may be related to folate deficiency [98]. High intake of folate $(0.8 \mathrm{mg})$ has been found to reduce the risk of IHD by $16 \%$, deep vein thrombosis by $25 \%$, and stroke by $24 \%$ [79]. However, the association between folate and CVD has mostly been explored through its effect on homocysteine. Folate is involved in the methylation of homocysteine to methionine. Folate deficiency is associated with increased blood levels of homocysteine, impaired synthesis/activity of endothelial NO, enhanced inflammatory processes that lead to vasoconstriction, atherosclerosis, and by extension CAD [99]. Folate supplementation has been found to decrease serum levels of homocysteine and its sequalae [100]. A high serum homocysteine level is associated with a higher risk of hypertension and stroke [101], however, other prospective studies have questioned the independent role of homocysteine as a risk factor for CVD [102]. Folate is thought to act as a cofactor for endothelial NO synthesis, inhibiting intracellular superoxide generation and stimulating endogenous tetrahydrobiopterm (an enzymatic cofactor of NO synthase), thereby leading to vasodilatation and decreasing the risk of CVD [99]. 


\subsection{Vitamin C deficiency and CVD}

Vitamin $\mathrm{C}$ is a water soluble antioxidant vitamin with potential to directly scavenge free radicals (singlet oxygen, superoxide and hydroxyl radicals) invitro (Figure 4).

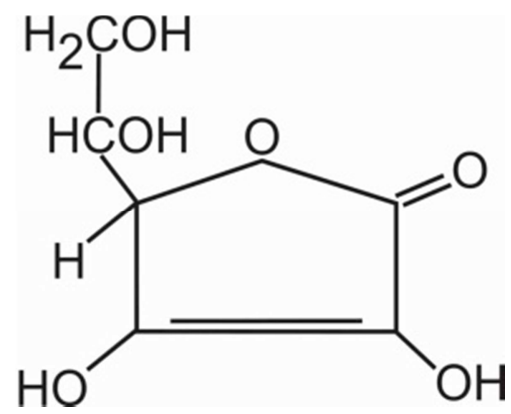

Figure 4. Chemical structure of vitamin $C$.

Sources of vitamin $\mathrm{C}$ include vegetables (e.g., broccoli, green and red pepper, and brussels), citrus, paya and strawberries. The hypothesis that increased intake of vitamin $\mathrm{C}$ is protective against $\mathrm{CVD}$ and associated morbidity and mortality is validated in many wellconducted population-based studies and clinical trials. Current data support the beneficial effect of vitamin $\mathrm{C}$ itself in primary prevention of CVD [47]. However, results of other studies have been less supportive, showing either negative $[103,104,105,106,107]$ or inconclusive data $[108,109,110,111,112]$. Many of these studies may have been confounded by several inappropriately adjusted for covariates, such as poor determination of serum vitamin $\mathrm{C}$ level; individual susceptibility factors, including lifestyle variables such as smoking and alcohol intake; the health status of the studied population; and dietary vitamin $\mathrm{C}$ intake. It is suggested that a modest intake of vitamin C (100 $\mathrm{mg} /$ day $)$ is optimal for maximum reduction of CHD risk among non-smoking men and women [113].

In the Nurses' Health Study, supplementation with vitamin $\mathrm{C}$ resulted in a $28 \% \mathrm{CHD}$ risk reduction. The first National Health and Nutritional Examination Study, an epidemiologic follow-up study, found a $45 \%$ and $25 \%$ reduction in CHD risk in men and women respectively, who consumed $>50 \mathrm{mg}$ /day of vitamin $\mathrm{C}$ from dietary sources and took regular supplementation equivalent to $300 \mathrm{mg} /$ day [109].

Osagnian et al., [47] in a report, showed consistent results with a $25 \%$ reduction in CHD among women who consumed vitamin $\mathrm{C}$ supplements, but not when obtained from the diet. Also, a prospective population based study of men from Eastern Finland showed inverse association between vitamin $\mathrm{C}$ deficiency and acute MI [114]. According to a study by Riemersma et al. [104], low plasma vitamin $\mathrm{C}$ was not associated with an increased risk of acute MI, irrespective of the smoking status of their study subjects. However, this study was limited by inability to measure plasma vitamin $\mathrm{C}$ levels in some patients, underestimation of the confounding effect of smoking, the differential response rate which was higher in patients than controls, and the likelihood of reporting bias. Another study used a semi-quantitative food frequency questionnaire which is not sensitive enough to detect small differences in CHD risk and hence, may not have detected an effect [47]. In contrast, a study that used a seven-day diet diary demonstrated a strong inverse association between CHD-related mortality and plasma vitamin C level [115].

Therefore, studies that detected significant associations with only vitamin $\mathrm{C}$ supplements [47] may have done so because it is easier to assess supplemental intake than dietary intake. Subjects can remember more easily the dose and frequency of supplement intake than exact dietary recall for a certain period of time. The use of a food frequency questionnaire is less precise and does not ccount for losses of vitamin $\mathrm{C}$ during storage and preparation. Some studies [116] associating vitamin C intake with adverse health effects (including increase risk of MI and death) were characterized by small sample sizes and a small number of deaths which could have been a chance finding, or may have been due to confounding. Dose-dose variation could confound results and produce discrepant data across studies. There is an optimum saturation dose at which cells and tissues are fully saturated and cardioprotective effects are enhanced [117]. Relatively high doses of vitamin $\mathrm{C}$ are required to inhibit the rapid reaction between superoxide and NO radicals in vivo [118].

According to Frei, [119], difficulties in accurately assessing vitamin $\mathrm{C}$ in epidemiologic studies could partly account for inconsistent results across studies. Some studies report reduced CHD risk within the dietary vitamin C intake range of $100 \mathrm{mg} /$ day, but not with supplementation [113, 115], whereas available pharmacokinetic studies document optimum cardioprotective effects at a full saturation daily dose of $400 \mathrm{mg}$ of vitamin C [117]. The cardioprotective potential of vitamin $\mathrm{C}$ lies in its antioxidant property. Oxidative stress generates ROS that destroys NO, an endothelial vasodilator, leading impaired endothelium mediated vasomotion. Vitamin $\mathrm{C}$ directly inactivates ROS and protects NO from being destroyed by free radicals. Vitamin $\mathrm{C}$ also enhances endothelial NO production by preventing the inactivation of tetrahydrobiopterin which acts as a co-factor to endothelial NO synthase [120].

\subsection{Vitamin D deficiency and CVD}

Vitamin D is a steroid-structured, fat-soluble vitamin produced in the skin as a result of exposure to sunlight [3], or from dietary sources such as oily fish [120], eggs, yolk, butter, liver, and fortified foods. Regardless of the source, vitamin $\mathrm{D}$ and its metabolites circulate bound to vitamin $\mathrm{D}$ binding protein. The peripheral circulating form of vitamin $\mathrm{D}$ is 25 -hydroxy vitamin $\mathrm{D}(25(\mathrm{OH}) \mathrm{D})$, while the most potent form is the 1,25 dihydroxy vitamin $\mathrm{D}(1,25(\mathrm{OH}) \mathrm{D})$ [121, 122] (Figure 5A). 


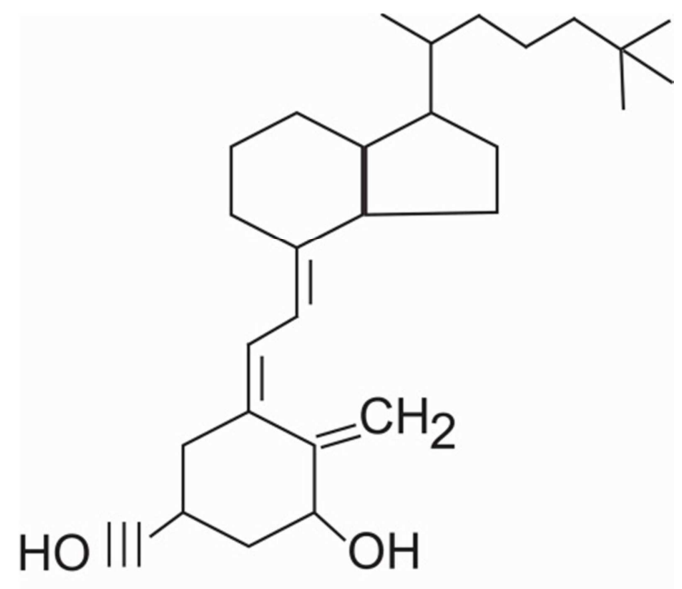

\section{$1,25(\mathrm{OH})_{2} \mathrm{D}_{3}$ (Calcitriol)}

Figure 5A. Chemical structure of $1,25(\mathrm{OH})_{2} \mathrm{D}_{3}$ (Calcitriol).

Recent studies indicate that vitamin D deficiency (hypovitaminosis D) is very common in the general population [3, 120, 123, 124]. Hypovitaminosis D is widespread and is seen even in areas with high levels of ultraviolet radiation and in developed countries where diets are fortified with vitamin $D$ [125]. It often remains unrecognized and untreated [122]. It is presumed that about 1 billion individuals worldwide may be deficient or have insufficient levels of vitamin D [3]. Links between vitamin D deficiency and cardiovascular pathologies have been established in several experimental clinical trials, crosssectional, prospective, and epidemiologic as well as preventive trials; available data indicate that vitamin $\mathrm{D}$ is potentially an important biomarker for CVD [126]. Vitamin $\mathrm{D}$ deficiency has been found to directly or indirectly impact several cardiovascular endpoints including hypertension, IHD, MI [122], endothelial dysfunction, slow coronary flow, subclinical atherosclerosis, and death due to CHD.

In a 10-year Health Professional Follow-Up Study of normal subjects at baseline, Giovanncci et al. found that subjects who subsequently developed low level of serum vitamin $\mathrm{D}(<15 \mathrm{ng} / \mathrm{mL})$ had twice the odds for $\mathrm{MI}$, independent of other covariates [153]. Within the same period, a study by Pilz et al. [127] showed that subjects who were deficient in vitamin $\mathrm{D}$ had a $50 \%$ increased odds for fatal stroke [127]. Their study findings confirmed a previous 10-year follow-up study by Marniemi et al. [128] that also associated vitamin D (25(OH)D) deficiency with MI and stroke in the elderly population [128].

An inverse association between plasma level of vitamin D and hypertension has been reported in human and animal models of vitamin D deficiency [125]. Moreover, plasma $25(\mathrm{OH}) \mathrm{D}$ deficiencies and vitamin $\mathrm{D}$ receptor polymorphism are correlated with hypertension. One animal study showed that disruption of the vitamin $\mathrm{D}$ receptor gene resulted in a rise in blood pressure, renin production, and cardiac hypertrophy (129). Furthermore, subjects with low plasma active vitamin $\mathrm{D}(25(\mathrm{OH}) \mathrm{D})$ levels $(<15 \mathrm{ng} / \mathrm{mL})$ had higher odds for current onset of hypertension within 4 years than those with normal vitamin D levels ( $>30 \mathrm{ng} / \mathrm{mL}$ ).

In the National Health and Nutrition Examination Survey, low plasma levels of vitamin D strongly predicted angina pectoris, MI, stroke [130], atrial fibrillation, and ventricular hypertrophy. In a prospective study of 1471 normal post-menopausal women, Bolland et al. [131] showed that women with a lower vitamin D level at baseline were more likely to have a higher fat mass, be physically inactive, positive history of IHD risks, dyslipidemia, and higher calculated cardiovascular risk at baseline than women with serum levels of $25(\mathrm{OH}) \mathrm{D}>50 \mathrm{nmol} / \mathrm{L}$ [131]. The consistency of the association between vitamin $\mathrm{D}$ deficiency and CVD has led to the suggestion that vitamin D should be considered a cardiovascular marker [121].

Although vitamin D supplementation has shown impressive cardio-protective potential in several studies, its cardioprotective effect has been challenged by studies showing negative correlations between vitamin $\mathrm{D}$ supplementation and cardio-protective effects. For instance, in the Women's Health Initiative study [132] and a randomized, double blind, controlled trial in Europe [133], vitamin D deficiency or supplementation produced no effect on cardiovascular endpoints. These discrepancies have been explained on the basis of inconsistencies/inadequacy in experimental doses, study population, and the effect of other coexisting nutrients [134].

Interestingly, despite the significant role of vitamin $\mathrm{D}$ in CVD, there is no consensus among researchers regarding what cut-off value should be used to define insufficient or deficient levels of vitamin D. However, an optimum level for cardio-protective effects has been proposed. According to Zittermann et al., [135], serum vitamin D level of 30-35 ng/L provides optimal cardio-protective effects [135].

Based on the Institute of Medicine, a daily intake of 400600 IU of vitamin D is recommended for an adult [136]. Others are of the opinion that a daily intake close to $1000 \mathrm{IU}$ of vitamin D is more appropriate to maintain health [137]. In most other studies vitamin D deficiency is defined as calcitriol level of $<20 \mathrm{ng} / \mathrm{mL}$, a level of $21-29 \mathrm{ng} / \mathrm{mL}$ is defined as insufficient, $30 \mathrm{ng} / \mathrm{mL}$ is regarded as sufficient, and $>150 \mathrm{ng} / \mathrm{mL}$ is defined as a toxic [138]. Currently, agespecific daily allowances have been suggested, with $200 \mathrm{IU}$ recommended for adults aged 20-50 years, 400 IU for adults $51-69$ years of age, and 600 IU for adults $\geq 70$ years. For the average older adult, $800 \mathrm{IU}$ is the recommended daily allowance. However, dark-skinned older adults with limited sun exposure may need $\geq 2000$ IU per day [134, 139].

Several risk factors for vitamin D deficiency have been identified, including obesity [131, 140], smoking [141], physical inactivity [131], skin color, reduced exposure to sunlight, diabetes mellitus, and variation in distance from the equator. Others include low HDL-C level, malabsorption, renal disease, and medications (such as anticonvulsants and corticosteroids).

The plausible mechanisms underlying the cardioprotective effects of vitamin D are complex and may include down-regulation of the renin-angiotensin-aldosterone system [121] (by decreasing renin-angiotensin activity or downregulating renin production by the kidneys (Figure $5 \mathrm{~B}$ ). 


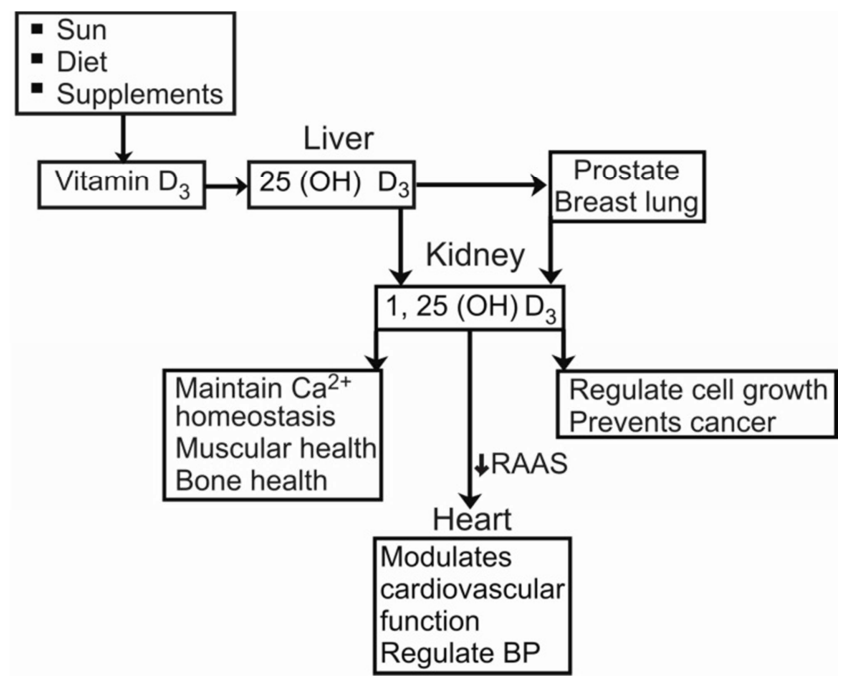

Figure 5B. Schematic representation of the pathways of vitamin $D$ biosynthesis and cardiovascular effects.

This inhibitory action of vitamin D on RAAS may provide indirect antioxidant effect due to the associated improvement in endothelial function as reported previously [142]. Angiotensin II mediated increased production of superoxide is the speculated pathophysiologic mechanism leading to endothelial damage.

Vitamin D inhibits this process and by extension preserves endothelial health [143]. This action significantly contributes to the cardio-protective effect of vitamin $\mathrm{D}$ in hypertension and congestive cardiac failure (CCF) as observed previously [129].

One study showed that vitamin D supplementation reduced the mortality risk of patients with renal failure [144]; suppression of the expression of renin genes and regulation of genes involved in renin production have been suggested as mechanisms. Furthermore, vitamin D is known to exert antiinflammatory effects via several pathways, including inhibition of prostaglandin and the cyclo-oxygenase pathway and up-regulation of anti-inflammatory cytokines. It is posited that vitamin D's anti-inflammatory activities have potential therapeutic benefits in several autoimmune diseases [134]. Vitamin D is also known to possess anti-atherogenic effects; hence, is cardio-protective. Low vitamin D levels may also indirectly affect cardiovascular endpoints due to its etiopathogenic role in several metabolic aberrations such as obesity, diabetes mellitus, dyslipidemia, and hypertension (and hence CVD) [126].

\subsection{Vitamin E Deficiency and CVD}

Vitamin E is a major lipid-soluble antioxidant, and is the most effective chain-breaking antioxidant within the cell membrane. Several studies have evaluated the role of vitamin $\mathrm{E}$ in CVD and have provided results that corroborate the hypothesis that vitamin $\mathrm{E}$ has a protective effect against atherosclerosis, and hence CVDs, independent of the effect of other potential confounders $[145,146,147]$. In the Nurses' Health Study [148], those in group with the highest intake of vitamin E had a $34 \%$ decreased coronary risk compared with those in the lowest intake group. Vitamin E supplementation provided a better reduction $(40 \%)$ than the dietary vitamin E. The Health Professional Follow-Up Study of 40,000 US male professionals aged 40-75 years provided similar results [110]. Likewise, the Iowa Women's Health Study [149] found an inverse association between vitamin E and CVD. However, in the latter, the association was strongest in the group taking supplements than the diet group. A study of middle-aged French Canadian Men [150] corroborated the aforementioned studies' findings. A cross-cultural study of 16 populations of men and women in the Multinational Monitoring of Trends and Determinants in Cardiovascular Disease study found a significant inverse association between vitamin $\mathrm{E}$ intake and IHD-related mortality $(\mathrm{RR}=$ $0.49 ; \mathrm{P}=0.01$ ) [151]. Two other cross-sectional studies [152, 153], among 6000 Scottish men aged 35-54 years found inverse association between plasma vitamin E level and angina. In a case-control study in Tunisia, Feki et al., [145], concluded that adequate intake of vitamin $\mathrm{E}$ from the diet or supplementation could prevent CHD.

Nevertheless, some other epidemiologic prospective studies found the converse, including the Multiple Risk Factor Intervention Trial, the Elderly Cohort Studies [154], the Rotterdam Study [155], the European Community Multicenter Study on Antioxidants, and the Gruppo Italiano per lo Studio della Sopravvivenza nell Infarto Miocardico prevention trial [156]. The lack of observed association in these studies may be attributable to uncontrolled confounding from unknown or unmeasured confounders such as exercise, diet, concurrent vitamin $\mathrm{C}$ depletion or deficiency, and background CVD risk of different study populations. These may produce effects similar in magnitude to the observed health effect. For instance, dietary antioxidants can produce effects similar to experimental antioxidants. Such effects could be additive or synergistic making it difficult to ascertain the specific benefit of the tested antioxidant vitamin [14]. Also, inaccuracies in determination of intake (e.g., dietary intake, vitamin supplementation, lipid standardized, or absolute vitamin E concentrations), changes in dietary habits during the follow-up period or a decrease in vitamin $\mathrm{E}$ concentration with time $[157 ; 158]$, and differences in the selection criteria of cases (e.g., questionnaires, medical examination, and vitamin E status determination) [145] may have impacted the results and weakened the association.

Previous studies [159, 160], mostly clinical trials, that showed lack of benefit of vitamin E supplementation in CVD were characterized by several methodologic flaws, including short period of treatment [160], low dose used [159], small number of events [160], advanced age and high baseline risk of CHD of participants [161], as well as the use of clinical events as endpoints $[159,160,161]$.

Vitamin E protects membrane fatty acids from lipid peroxidation by preventing the lipid peroxidation chain reaction in the LDL-C particle [162]. Vitamin E supplementation has been shown to decrease lipid 
peroxidation by as much as $40 \%$ [162]. Oxidized LDLs are atherogenic due to their immunogenicity, cytotoxicity, and chemotaxic properties [163]. Therefore, the antiatherosclerotic effect of vitamin $\mathrm{E}$ is strongest at the point of initiation (primary prevention) than in an already established atherosclerotic lesion (secondary prevention) $[145,164]$. This hypothesis is in agreement with results obtained by Klein et al. in a study to assess the effect of two different combined treatments with vitamin $\mathrm{E}$ acetate and vitamin $\mathrm{C}$ on infarct size and recovery of regional myocardial function [165]. Initiation of treatment before the onset of ischemia resulted in a greater reduction in infarct size and better recovery of regional myocardial function than initiation of treatment during ischemia.

Vitamin E also has the potential to prevent other deleterious processes leading to atherosclerosis. It decreases the secretion of IL-1, reduces platelet adhesion and aggregation [166], decreases monocyte endothelial cell adhesion, and inhibits thrombin formation [165]. Thus, vitamin $\mathrm{E}$ intake may have a greater protective effect against the onset of primary atherosclerotic lesions (identified using imaging criteria as endpoints) in younger individuals with a CHD-free background and a prolonged period of intake $(>10$ years) than in older individuals with pre-existing atherosclerotic lesions, a high CHD risk background, and with short duration of therapy ( $<5$ years) using clinical event endpoints [145], as characteristic of most clinical trials and secondary prevention studies. However, most observational studies support the protective effect of vitamin E against CHD [151].

The mechanism underlying the cardio-protective effects of vitamin $\mathrm{E}$ include stabilization of plaque, reduction of platelet adhesion and aggregation, expression of adhesion molecule on the arterial wall, and reduction of vasodilatation [162]. Thus, vitamin E protects against atherosclerosis and, by extension, $\mathrm{Ml}$ and thrombotic stroke [162]. Adequate levels of vitamin $\mathrm{C}$ are required for the reduction of oxidized vitamin $\mathrm{E}$. Reduced vitamin $\mathrm{E}$ is very important because it can be re-utilized by cells for free radical scavenging in lipophilic sites [119]. However, recent evaluation of the supplementary use of vitamin $\mathrm{E}$ for prevention of CVD by the US Preventive Services Task Force found moderate evidence against supplementation with vitamin $\mathrm{E}$ for the prevention of CVD or cancer [59].

\section{Micronutrient Combination/Interaction and Effect on CVD}

There is compelling evidence that multiple micronutrient deficiencies (MNDs) may be associated with a higher risk of CVD than single MNDs. Likewise, multiple micronutrient supplementation in pharmacologic doses may provide better relief from multiple MND-induced CVD than micronutrient monotherapy. Obviously, paired micronutrient supplementation is more likely to address the pleotropic etiology of adverse cardiovascular endpoints than micronutrient monotherapy. The pathophysiologic mechanisms underlying MND-induced vascular abnormalities (e.g., endothelial damage, smooth muscle and cardiac muscle dysfunction, vascular disease, and atherosclerosis) leading to CVD, are etiologically related to oxidative stress, inflammation, and autoimmune dysfunction and are also closely interrelated. Therefore, supplementation of paired micronutrients with antioxidant, anti-inflammatory, and immune boosting potential would provide a synergistic/additive cardio-protective effect than micronutrient monotherapy. Paired micronutrient supplementation can also precipitate interactions between micronutrients. For instance, high manganese supplementation leads to magnesium deficiency and CVDs, with manganese acting as a potential magnesium antagonist [168]. Several previous studies showed that adequate intake of some micronutrients could enhance the pharmacokinetic and/or the pharmacodynamic potentials of other micronutrients.

For instance, some micronutrients act as cofactors for the biosynthesis, transport, activation, and effect of others, while others enhance the absorption and metabolism of other micronutrients. In addition, some micronutrients gain protection from the auto-oxidation by the antioxidant activities of other micronutrients. Some vitamins affect the requirement for other vitamins or minerals and vice versa. A study showed that although an adequate amount of potassium was administered, the serum potassium level did not improve until magnesium was co-administered [169]. Adequate serum magnesium enhances both the absorption and effects of potassium. Similarly, studies have suggested the confounding effect of magnesium and vitamin $\mathrm{D}$, or possible interaction between the two. One study observed a lack of clinical and biochemical improvement in rickets patients treated with vitamin D until magnesium was supplemented [170]. Studies by Rude et al. [171] and Fuss et al. [172] showed that high doses of vitamin D alone failed to cause improvement in serum levels of both $25(\mathrm{OH}) \mathrm{D}$ and $1,25(\mathrm{OH})_{2} \mathrm{D}$ in vitamin $\mathrm{D}$ deficiency states until magnesium and vitamin $\mathrm{D}$ were co-administered. Administration of high doses of magnesium modified the inverse association of serum 25(OH)D and CVD mortality, according to Rosanoff et al. [173], who cited Deng et al. [174]. Earlier studies showed that calcium intake affects magnesium retention, and vice versa [175], and that hypomagnesemia is often present with hypocalcemia [171]. Furthermore, co-administration of vitamin $\mathrm{C}$ prevents magnesium deficiency-induced heart failure, probably due to the ability of vitamin C to scavenge ROS [176].

Similarly, the cardio-protective effect of vitamin $E$ is enhanced and sustained when co-administered with vitamin C [154] due to the synergistic antioxidant effect of both vitamins. The antioxidant activity of alpha-tocopherol results in the production of toxic tocopherol radicals, which are reconverted into alpha-tocopherol by vitamin $\mathrm{C}$ and are then reutilized (Figure 6). 


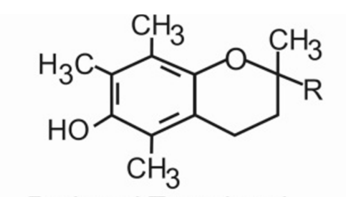

Reduced Tocopherol

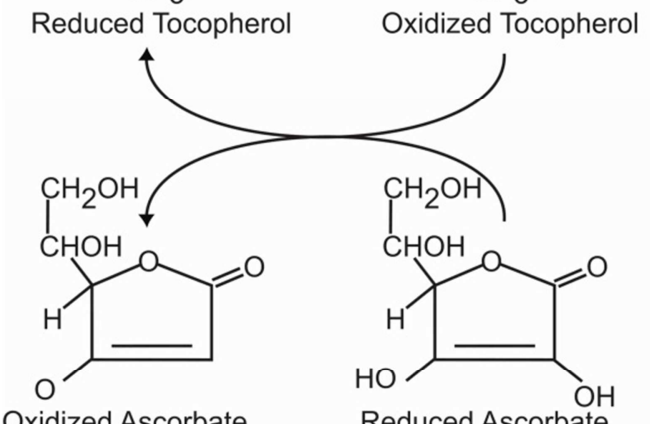

Oxidized Ascorbate

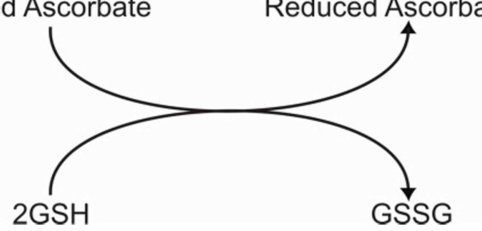

e

\section{.}

$$
\text { GSSG }
$$

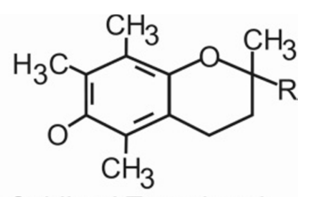

Figure 6. Reduction of oxidized ascorbate by glutathione enhances the reduction of oxidized tocopheryl by the reduced ascorbate. This increases the availability of reduced tocopherol for reutilization.

Kennedy and Liebler [177] and Palozza and Krinsky [178] found that tocopherol protects carotenoids from autooxidation. Likewise, vitamin $\mathrm{C}$ protects tocopherol and $\beta$ carotene from oxidative damage $[179,180]$. Singh et al. [181] found that vitamins A, C, E, and $\beta$-carotene attenuated acute MI a few hours after onset causing a significant decline in total adverse cardiac endpoints [181]. This action was faster and better than the effect of micronutrient monotherapy. Witte et al, [182] used multiple micronutrient supplementation to ameliorate chronic heart failure and IHD and improved quality of life in septuagenarian patients. In a related study, pure selenium deficiency symptoms were found to be rare, but were demonstrated to become obvious when vitamin E deficiency co-occu rs with selenium deficiency [182]. Chen et al. [72] reported a higher risk of hyperhomocysteinemia when the deficiency of vitamin $\mathrm{B}_{2}$ or $\mathrm{B}_{6}$ co-occurred with folate deficiency.

The aforementioned studies indicate that paired micronutrient supplementation or deficiencies may provide a greater cardioprotective or cardiotoxic effects, respectively, than micronutrient monotherapy, provided treatment with pharmacologic doses is ensured. It should be noted that inappropriate combination doses may result in adverse health outcomes. For instance, supplementation with a high manganese diet exacerbated magnesium deficiency and death in animals fed a high manganese-low magnesium diet compared with animals fed a low manganese-magnesium deficient diet [183]. Furthermore, it is the ratio of copper to zinc in the zinc-copper superoxide dismutase-1 enzyme complex, rather than the absolute amount of copper or zinc, that provides the enzyme complex with higher superoxide scavenging potential and more efficient anti-inflammatory and cardioprotective effects [184]. In support of this view, Reunanen et al., [185], in a study evaluating the association of serum calcium, magnesium, copper, and zinc concentrations with cardiovascular mortality, reported a higher risk of CHD with the higher risk of CHD-related mortality among those treated with the highest and lowest tertiles of serum copper and zinc.

This may explain, in part, the lack of association between the deficiency of some micronutrients (in some populations) and cardiovascular endpoints as the baseline level of some complementary micronutrients were not determined in most of these studies. Evidently, the effect of one micronutrient may depend on the complementary actions of other micronutrients when present in physiologically relevant levels or at pharmacologic doses.

\section{Conclusion}

Although opinions are conflicting, there is substantial, significant evidence to suggest that MVD is widespread and is related to adverse cardiovascular endpoints. The lack of association in some studies could partly be due to lack of adequate adjustment for several covariates, including deficiencies in some complementary micronutrient pairings. Supplementation with single or paired micronutrients for prevention of CVD in those with widespread MVDs, pregnant women, children, chronically ill or hospitalized individuals or those known to have nutritional deficiency would be practical and attractive, and is therefore recommended. There is not enough evidence to support supplementation of single or paired micronutrients for prevention of CVD in healthy, well-nourished populations without known nutritional deficiencies. More studies are needed to further assess the usefulness of single or combined micronutrients in healthy populations and in those with adequate micronutrient levels at baseline. Pairing of complementary micronutrients in pharmacologic doses may improve potency, metabolism, and outcomes and may minimize resistance and toxicity.

\section{Abbreviations}

$\mathrm{CAD}$, coronary artery disease; CHD, coronary heart disease; CRP, C-reactive protein; CVD, cardiovascular disease; DNA, deoxyribonucleic acid; hs-CRP, high sensitivity C-reactive protein; HDL-C, high-density lipoprotein cholesterol; IL-IB, interleukin-IB; IL-6, interleukin-6; IHD, ischemic heart disease; MNV, micronutrient vitamin; MVD, micronutrient vitamin deficiency; LDL-C, low-density lipoprotein cholesterol; MI, myocardial infarction; NHANES, National Health and Nutrition Examination Study; NO, nitrous oxide; ROS, reactive oxygen species; TNF- $\alpha$, tumor necrosis factor alpha.

\section{References}

[1] Voutilainen S, Nurmi T, Mursu J, Rissanen TH. Carotenoids and Cardiovascular health. Am J Clin Nutr 2006; 83 (6): 126571. 
[2] Mathers CD, Loncar D: Projections of global mortality and burden of disease from 2002 to 2030. PLoS Med 2006; 3 (11): e442.

[3] Liu M, Li C, Sun R, Zeng Y, Chen S, Zhang P. Vitamin D nutritional status and the risk for cardiovascular disease (Review). Expt Ther Med 2016; 11 (4): 1189-93.

[4] Vijayaraghavan K. Treatment of dyslipidemia in patients with type-2 dubieties. Lipids in health and disease 2010, 9: 144. Doi.101186/1476: 511X-9-144.

[5] Gayathri K, Jayachandran KS, Vasanthi HR, Rajamanickam GV. Cardio-protective effect of lemongrass as evidenced by biochemical and histopathological changes in experimentally induced cardiotoxicity. Human and experimental toxicology 2011: 30 (8): 1073-82.

[6] Guallar E, Jiménez FJ, Van 't Veer P, Bode P, Riemersma RA, Gómez-Aracena $\mathrm{J}$ et al. Low toenail chromium concentration and increased risk of nonfatal myocardiac infarction. Am J Epidemiol 2005; 162 (2): 157-64.

[7] Barker DP. In utero programming of chronic disease. Clinical Science 1998a; 95: 115-128.

[8] Barker DP. Mothers, babies and health in later life. $2^{\text {nd }}$ ed. Edinburgh: Churchill Livingstone 1998b.

[9] Ravelli AC, an der Meulan JH, Michels RP, Osmond C, Barker DJ, Hales CN. Glucose tolerance in adults after prenatal exposure to famine. Lancet 1998; 350: 173-77.

[10] Rosario JF, Gomez MP, Anbu P. Does the maternal micronutrient deficiency (copper or zinc or vitamin E) modulate the expression of placenta $11 \beta$ hydroxysteroid dehydrogenase -2 per se predispose offspring to insulin resistance and hypertension in later life? Indian $\mathrm{J}$ Physiol Pharmacol 2008; 52: 355-65.

[11] Stewart CP, Christian P, Schulze KJ, Leclerq SC, West KPJr, Khatry SK. Antenatal micronutrient supplementation reduces metabolic syndrome in 6- to 8- year-old children in rural. Nepal J Nutr 2009; 139: 1575-81.

[12] Christian P, Stewart CP. Maternal micronutrient deficiency, fetal development and the risk of chronic disease. J Nutr 2010; 140: 437-45.

[13] Prohaska JR, Copper. In: Erdman JW, Macdonald IA, Zeisel SH. Eds. Present knowledge in Nutrition $10^{\text {th }} \mathrm{Ed}$. Anies: Wiley-Blackwell, 2012: 540-53.

[14] Gaziano JM. Vitamin E and cardiovascular disease: observational studies. Ann N Y Acad Sci 2004; 1031: 280-91.

[15] Toole TF, Mahnow MR, Chambless LE, Spence JD, Pettigrew LC, Howard VJ, et al. Lowering homocysteine in patients with ischemic strole to prevent recurrent stroke, myocardial infarction and death: the Vitamin Intervention for Stroke Prevention (VISP) randomized controlled-trial. JAMA 2004; 291: $565-75$.

[16] Spence JD, Bang H, Chambles LE, Stampfer MJ. Vitamin Intervention for Stroke Prevention trial: an efficacy analysis. Stroke 2005; 36 (11): 2404-9.

[17] Spence JD. Homocysteine: call off the funeral. Stroke 2006; 37 (2): 282-3.

[18] Rajpathak S, Rimm EB, Li T, Morris JS, Stampfer MJ, Willet WC, et al. Lower toenail chromium in men with diabetes and cardiovascular disease compared with healty men. Diabetes care 2004: 27 (9): 2211-6.

[19] Bonaa KH, Njolstad I, Ueland PM, Schirmer H et al. Homocysteine lowering and cardiovascular events after acute myocardial infarction. N Engl J Med 2006; 354 (15): 1578-88.

[20] Leone N, Courbon D, Ducimetiere P, Zureik M. Zinc, copper and magnesium and risks for all cause, cancer, and cardiovascular mortality. Epidemiology 2006; 17 (3): 308-14.

[21] Ebbing M, Bleie O, Ueland PM, Nordrehaug JE, Nilsen DW, Vollset SE, et al. Mortality and cardiovascular events in patients treated with homocysteine-lowering B vitamins after coronary angiography: a randomized controlled trial. JAMA 2008; 300 (7): 795-804.

[22] Henderson L, Irving K, Gregory JF, Bates CJ, Pentice A, Perks J, Swan G, Farron M. The National Diet and Nutrition Survey: Adults Aged 19 to 64 years. Vol 3: vitamin and mineral intake and urinary analyst. 2003; vol. 3: ISBN: 0116215682 London: The stationary office.

[23] Van Rossum CT, Fransen HP, Verkaik-Kloosterman J, Buurma-Rethans EJ, Ocke MC. Dutch National Food Consumption survey 2009-2010: Diet of Children and Adults Aged 7 to 69 years. 2011; Bilthoven: RIVM. Report no. 350050006/2011. Bilthoven; National Institute for Public Health and the Environment.

[24] Ecker O, Weinberger K, Qaim M. Patterns and determinants of dietary micronutrient deficiencies in rural areas of East Africa. Afecan Journal of Agricultural and Resource Economic 2010: 4 (2); 175-94.

[25] Schroeder HA, Nason AP, Tipton IH. Chromium deficiency as a factor in atherosclerosis. J. Chronic Dis 1970; 23 (2): 123-42.

[26] Althuis MD, Jorden NE, Ludington EA, Wiltes JT. Glucose and insulin responses to dietary chromium supplements: a meta-analysis. Am J Clin Nutr 2002; 76: 148-55.

[27] Newman HA, Lelghton RF, Lanese RR, Freedland NA. Serum chromium and angiographically determined coronary artery disease. Clin Chem 1978; 24 (4): 541-44.

[28] Simonoff M, Llabador Y, Hamon C, Peers AM, Simonoff GN. Low plasma chromium in patients with coronary artery and heart disease. Biol Trace Elem Res 1984; 6 (5): 431-39.

[29] Swecker BJ, Chromium. In: Shils ME, Olson JA, Shike M et al, eds. Modern nutrition in health and disease. Baltimore, MD: Williams and Wilkins company, 1999: 277-82.

[30] Panel on Micronutrients, Food and Nutrition Board, Institute of Medicine. Dietary reference intakes for vitamin A, Vitamin $\mathrm{K}$, arsenic, boron, chromium, copper, iodine, iron manganese, molybdenum, nickel, silicon, vanadium, and zinc Washington, DC: National Academy Press, 2001.

[31] Houston MC. The role of nutrition and nutraceutical supplements in the treatment of hypertension. World J Cardiol 2014: 6 (2) 38-66.

[32] Tribble DL. Antioxidant consumption and risk coronary heart disease. Emphasis on vitamin $\mathrm{C}$, vitamin $\mathrm{E}$, and $\beta$-carotene. A statement for health professionals from the Am Heart Assoc Circ 1999; 99: 591-95.

[33] Soydinc S, Celik A, Demiryurek S, Davutoglu V, Taracioglu $\mathrm{M}$, Aksoy M. The relationship between oxidative stress, nitric oxide and coronary artery disease. Eur J Gen Med 2007; 4 (2): $62-6$. 
[34] Wattanapitayakul SK, Bauer JA. Oxidative pathways in cardiovascular disease. Roles, mechanisms, and therapeutic implications. Pharmacol Ther 2001: 89: 187-206.

[35] Fortmann SP, Burda BU, Senger CA, Lin SJ, Whitlock EP. Vitamin and Mineral supplements in the primary prevention of cardiovascular diseases and cancer: An updated systematic evidence review for the U.S preventive services task force. Ann Intern Med 2013; 159 (12): 824-34.

[36] Gorski PA, Ceholski DK, Hajjar RJ. Altered myocardial calcium cycling and energetic in heart failure-a rational approach for disease treatment. Cell Metab 2015: 21 (2): 18394.

[37] Khan AM, Sullivan L, McCabe E, Levy D, Vasan RS, Wang TJ. Lack of association between serum magnesium and the risks of hypertension and cardiovascular disease. am Heart $\mathrm{J}$ 2010; 160 (4): 715-20.

[38] Slow RC, Richards JP, Pedley KC, Leeke DS and Mann GE. Vitamin C proteins human vascular smooth muscle cells against apoptosis induced by moderately oxidized LDL containing high levels of lipid hydroperoxides. Arterioscler Thromb Vasc Biol 1999; 19: 2387-94.

[39] Ludwig DS. The glycemic index: physiological mechanisms relating obesity, diabetes and cardiovascular disease. J Am Med Assoc 2002; 287: 2414-23.

[40] Wolever TM, Jenkins DJ. The use of the glycemic index in predicting the blood glucose response to mixed meals. Am J Clin Nutr 1986; 43: 167-72.

[41] Beck-Nielsen H. Insulin resistance: organ manifestation and cellular mechanism. Ugeskr Laeger 2002; 164: 2130-35.

[42] Reaven GM. Insulin resistance and its consequences. In: Le Roith D, Taylor SI, Olefasky JM, eds. Diabetes mellitus: a fundamental and clinical text. 3rd ed. Philadelphia: Lippincott, Williams and Wilkins 2004; 899-915.

[43] Chiplonkar SA, Agte VV, Tarwadi KV, Paknikar KM, Diwate UP. Micronutrient deficiencies as predisposing factors for hypertension in lacto-vegetarian Indian adults. J Am Coll Nutr. 2004: 23 (3); 239-47.

[44] Houston MC. The role of cellular micronutrient analysis, nutraceuticals, vitamins, antioxidants and minerals in the prevention and treatment of hypertension and cardiovascular diseases. Ther Advan Cardiovasc Dis 2010: 4 (3); 165-83.

[45] Patrick L. ßeta-carotene: the controversy continues. Altern Med 2000; 5 (6): 350-545.

[46] Tulchinsky TH. Micronutrient deficiency condition: Global Health Issues. Pub Health Rev 2010, 32 (1), 243-55.

[47] Osganian SK, Stampfer MJ, Rimm E, Spiegelman D, Manson JE, Willet WC. Dietary carotenoids and risk of coronary disease in women. Am J Clin Nutr 2003; 77: 1390-9.

[48] Morris DL, Kritchevsky SB, Davis CE. Serum carotenoids and coronary heart disease. The Lipid Research Clinics Coronary Primary Prevention Trial and Follow-up Study. JAMA 1994; 272 (18): 1439-41.

[49] Gaziano JM, Manson JE, Branch LG, Colditz GA, Willet WC, Buring JE. A prospective study of consumption of carotenoids in fruits and vegetables and decreased cardiovascular mortality in the elderly, Ann Epidemiol 1995; 5 (4): 255-60.
[50] Tavani A, Negri E, D’Avanzo B, La Vecchia C. Beta-carotene intake and risk of nonfatal acute myocardial infarction in women. Eur J Epidemiol 1997; 13 (6): 631-37.

[51] Hennekens CH, Buring JE, Manson JE, Stampfer M, Rosner B, Cook NR, et al., Lack of effect of long-term supplementation with beta carotene on the incidence of malignant neoplasms and cardiovascular disease. $\mathrm{N}$ Engl $\mathrm{J}$ Med 1996; 334: 1145-49.

[52] Hak AE, Stampfer MJ, Campos H, Sesso HD, Gaziano MJ, Willet W, et al. Plasma carotenoids and tocopherols and risk of myocardial infarction in a low-risk population of US male physicians. Circulation 2003; 108: 802-7.

[53] Omen GS, Goodman GE. Thornquist MD, Balmes J, Cullen MR, Glass A, et al. Effects of combination of beta carotene and vitamin $\mathrm{A}$ on lung cancer and cardiovascular disease. $\mathrm{N}$ Engl J Med 1996; 334 (18); 1150-55.

[54] Csepanyi E, Czompa A, Haines D, Lekli I, Bakondi E, Balla $\mathrm{G}$, et al. Cardiovascular effects of low versus high-dose betacarotene in a rat model. Pharmacol Res 2015: 100; 148-56.

[55] Street DA, Comstuck GW, Salkeld RM, Schuep W, Klag MJ. Serum antioxidants and myocardial infarction. Are low levels of carotenoids and alpha-tocopherol risk factors for myocardial infarction? Circulation 1994; 90: 1154-61.

[56] Dwyer JH, Navab M, Dwyer KM, Hassan K, Sun P, Shircore $\mathrm{A}$, et al. Oxygenated carotenoids lutein and progression of early atherosclerosis: the Los Angeles atherosclerosis study. Circulation 2001; 103 (24): 2922-27.

[57] Dixon ZR, Burn BJ, Clifford A, Frankel EN, Schneeman BO, Parks E, et al. Effects of a carotene deficient diet on measures of oxidative susceptibility and superoxide dismutase activity in adult women. Free Radic Biol Med 1994: 17 (6): 537-44.

[58] Gottlieb K, Zarling EJ, Mobarhan S, Bowen P. Sugerman S. Beta carotene decreases markers of lipid peroxidation in healthy volunteers. Nutr. Cancer 1993; 19 (2): 207-12.

[59] Moyer VA. Vitamin, Mineral, and multi-vitamin supplements for the primary prevention of cardiovascular disease and cancer. U.S. Preventive services task force recommendation statement. Ann Intern Med 2014: 60 (8): 558-64.

[60] Stahl W, Sies H, Physical quenching of singlet oxygen and cis-trans isomerization of carotenoids. Ann N Y Acad Sci 1993; 691: 10-9.

[61] Mottaghi A, Salehi G, Keshvarz A, Sezavar H, SaboorYaraghi A-A. The influence of vitamin A supplementation on FOXP $^{3}$ and TGF-Gene Expression in Atheroscleratic Patients. J. Nutrigenet Nutrigenomics 2012; 5: 314-26.

[62] Zeba AN, Delisle HF, Rossier C, Renier G. Association of high-sensitivity $\mathrm{C}$-reactive protein with cardiometabolic risk factors and micronutrient deficiencies in adults of Ouagadougou, Burkina Faso. Br J Nutr 2012; 109 (7): 126675.

[63] Ridker PM, Rifai N, Rose L, Buring JE, Cook NR. Comparison of C-reactive protein and low-density lipoprotein cholesterol levels in the prediction of first cardiovascular events. N Engl J Med 2002; 347 (20): 1557-65.

[64] Leslie AG. Integration of macromolecular diffraction data. Acta Crystallogr D Biol Crystallogr 2006; 62 (pt1): 48-57. 
[65] Nijmeijer R, Lagrand WK, Lubbers YTP, Visser CA, Meijer CJL, Niessen HW, Hack CE. C-reactive protein activated complement in infracted human myocardium. American J. of Pathology 2003: 163 (1): 269-75.

[66] Kang SG, Lim HW, Andrisani OM, Broxmeyer HE, Kim CH. Vitamin A metabolites induce gut-homing $\mathrm{FOXP}^{+}$regulatory T-cells. J Immunol 2007; 179 (6): 3724-33.

[67] Elias KM, Laurence A, Davidson TS, Stephens G, Kanno Y, Shevach LM, O' Shea JJ: Retinoic acid inhibits Th 17 polarization and enhances FOXP3 expression through a stat3/stat-5 independent signaling pathway. Blood 2008; 111 (3): 1013-28.

[68] Schambach F, Schupp M, Lazar MA, Reiner SL. Activation of retinoic acid receptor-alpha favors regulatory $\mathrm{T}$-cell induction at the expense of IL-17-Secerting T-helper cell differentiation. Eur J Immunol 2007; 37 (9): 2396-99.

[69] Ntaios G, Savopoulos C, Grekas D, Hatzitolios. The controversial role of B-vitamins in cardiovascular risk: an update. Archives of cardiovascular disease 2009; 102, 847-54.

[70] Carmel R, Jacobsen DW, editors. Homocysteine in Health and Disease. Cambridge UK: Cambridge University Press 2001.

[71] Nygârg O, Vollset SE, Refsum $\mathrm{H}$ et al. Total plasma homocysteine and cardiovascular risk profile. The Hordaland homocysteine study. JAMA 1995: 274; 1526-33.

[72] Chen K-J, Pan W-H, Yang F-L, Wei I-L, Shaw N-S, Lin B-F. association of $\mathrm{B}$ vitamins status and homocysteine levels in elderly Taiwanese. Asia Pac J Clin Nutr 2005; 53 (6): 73139 .

[73] Harker LA, Harlan JM, Ross R. Effect of sulfinpyrazone on homocysteine induced endothelial injury and arteriosclerosis in baboons. Circ Res 1983; 53 (6): 731-39.

[74] Welch GN, Loscalzo J. Homocysteine and atherothrombosis. N. Engl J. Med 1998; 338: 1042-50.

[75] Harker LA, Slichter SJ, Scott CR, Ross R. Homocysteinemia: Vascular injury and arterial thrombosis. N Engl J Med 1974; 291: 537-43.

[76] Abraham JM, Cho L. The homocysteine hypothesis: still relevant to the prevention and treatment of cardiovascular disease? Cleve. Clin J Med 2010: 77 (12); 911-18.

[77] Yap S, Boers GH, Wilcken B, Wikken DE, Breton DP, Lee PJ, et al., Vascular outcome in patients with homocysteinuria due to cystathione beta-synthase deficiency treated chronically; a multi-center observational study. Arteriosler. Thromb Vasc Biol 2001; 21 (12): 2080-85.

[78] Schnyder G. Roffi M. Flammer Y, Pin R, Hess OM. Effect of homocyusteine lowering therapy with folic acid, vitamin $\mathrm{B}_{12}$, and vitamin $\mathrm{B}_{6}$ on clinical outcomes after percutaneous coronary intervention: the swiss heart study: a randomized controlled trail. JAMA 2002: 288: 973-70.

[79] Wald DS, Law M, Morris JK. Homocysteine and cardiovascular disease evidence on causality from a metaanalysis. British Medical Journal 2002: 325: 1202-8.

[80] Lindgren A, Brattstrom L, Norving B, et al. Plasma homocysteine in the acute and convalescent phase after stroke. Stroke 1995 ; 26: 795-800.

[81] Cheng SW, Ting AC, Wong J. Fasting total plasma homocysteine and atherosclerotic peripherail vascular diseases. Ann Vasc Surg 1997: 11 (3): 217-23.

[82] den Heijer M, Koster T, Bloin HJ, Bos GMJ, Briet E, Reitsma $\mathrm{PH}$, et al., Hyperhomocysteinemia as a risk factor for deepvein thrombosis N Engl J Med 1996: 334; 759-62.

[83] Molgaard J, Malinow MR, Lassvik C, Holm AC, Upson B, Olsson AG. Hyperhomocysteinaemia: an independent risk factor for intermittent claudication. J Inter Med 1992: 231 (3); 273-9.

[84] Nygard O, Nordrehaug JE, Refsum H, Ueland PM, Farstad M, Vollset SE, et al. Plasma homocysteine levels and mortality in patients with coronary artery diseases. N Engl J Med 1997; 337: 230-6.

[85] Adekunle AS and Adedeji AL. Anti-atherogenic effect of supplementation with vitamin $\mathrm{B}_{6}$ (Pyridoxine) in albino rats. African Journal of Biochemistry Research 2011; 5 (13): 3525.

[86] Rimm EB, Willett WC, Hu FB, Sampson L, Colditz GA, Mason JE, et al. Folate and vitamin $\mathrm{B}_{6}$ from diet and supplements in relation to risk of coronary heart disease among women. JAMA 1998: 279: 359-64.

[87] Merchant AT, Hu FB, Spiegelman D, Willett WC, Rimm EB, Ascherio A. The use of B vitamin supplements and peripheral arterial disease risk in men are inversely related. J. Nutr. 2003; 133 (9): 2863-67.

[88] Cui R, Iso H, Date C, Kikuchi S Tamakoshi A. Japan collaborative cohort study group. Dietary folate and vitamin $\mathrm{B}_{6}$ and $\mathrm{B}_{12}$ intake in relation to mortality from cardiovascular disease: Japan Collaborative cohort study. Stroke 2010; 41 (6): 1285-89.

[89] Mosca L. Novel cardiovascular risk factors: do they add value to your practice? Am Fam Physician 2003; 67: 264-66.

[90] Anderson RA. Natritional factors influencing the glucose/insulin system: chromium. J Am Coll Nutr 1997; 16 (5): 404-10.

[91] Lonn E. Homocysteine-lowering B vitamin therapy in cardiovascular prevention-wrong again? JAMA 2008; 299: 2086-87

[92] Milani RV, Lavie CJ. Homocysteine: the Rubik's cube of cardiovascular risk factor. Mayo Clin Proc 2008; 83: 1200-2.

[93] Bazzano LA. Folic acid supplementation and cardiovascular disease: the state of the art. Am J Med Sci 2009; 338: 48-9.

[94] Albert CM, Cook NR, Gaziano JM, Zaharris E, MacFadyyen J, Danielson E, et al., Effect of folic acid and B-vitamins on risks of cardiovascular events and total mortality among women of high risk of cardiovascular disease: a randomized trail. JAMA 2008; 299: 2027-36.

[95] SEARCH collaborative Group: Armitage IM, Bowman I, Clarke RI et al. Effects of homocysteine lowering eith folic acid plus vitamin $B_{12}$ Vs placebo on mortality and major morbidity in myocardial infarction survivors: a randomized trail JAMA 2010: 303 (24); 2486-94.

[96] Omid T-S, Heiko K, Alexandra W, Heike S, Natalia U, Ulrich $\mathrm{H}$, et al. The Cardiac effects of prolonged vitamin $\mathrm{B}_{12}$ and Folate deficiency in rats. Cardiovasc Toxicol 2009; 9 (2): 95 102. 
[97] Brown BG, Zhao XQ, Chait A, Fisher LD, Cheung MC, Morse JS, et al. Simvastatin and niacin, antioxidant vitamins, or the combination for the prevention of coronary disease. $\mathrm{N}$ Engl J Med 2001; 345 (22): 1583-92.

[98] UNICEF and Micronutrient Initiative. Vitamin and mineral deficiencies: a global progress report. Ottawa (Canada): The Micronutrient Initiative 2004

[99] Das S, Periyasamy R, Pandey KN,. Activation of IKK/NFkappa beta provokes renal inflammatory responses in guanylyl cyclase 1 natriuretic peptide receptor- A gene-knockout mice. Physiol Genomics 2012; 44: 430-42.

[100] Brouwer IA, van Dusseldorp M, Thomas CM, Duran M, Hautvast JG, et al. Low dose folic acid supplementation decrease plasma homocysteine concentrations: a randomized trial. Am J Clin Nutr 1999: 69; 99-104.

[101] Ridker PM, Manson JE, Buring JE Shih J, Matias M, Hennekens $\mathrm{CH}$. Homo cysteine and risk of cardiovascular diseases among post menopause women. JAMA 1999, 281: 1817-21.

[102] Ueland PM et al. The controversy over homocysteine and cardiovascular risk. Am J Clin Nutr 2000; 72: 324-32.

[103] Gey KF, Moser UK, Jordan P, Stahelin HB, Eichholzer M, Ludin E. Increased risk of cardiovascular diseases at suboptimal plasma concentrations of essential antioxidants: an epidemiological update with special attention to carotene and vitamin C. Am J Clin Nutr 1993; 57 (suppl 5): 787S-97S.

[104] Riemersma RA, Carruthers KF, Elton RA, Fox KAA. Vitamin $\mathrm{C}$ and the risk of acute myocardial infarction ${ }^{1-3}$. Am J Clin Nutr 2000; 71: 1181-6.

[105] Tunstall-Pedoe H, Woodward M, Tavendale R, Brook RA, McClusky MK. Comparison of the prediction by 27 different factors of cocronary heart disease and death in men and women of the Scottish Heart Study: cohort study. BMJ 1997; 315: 722-9.

[106] Vita JA, Keaney JF, Raby KE, Morow JD, Freedman JE, Lynch $\mathrm{S}$, et al. Low plasma ascorbic acid independently predicts the presence of an unstable coronary syndrome. J Am Coll Cardiol 1998; 31: 980-6.

[107] Myung SK, Ju W, Cho B, Oh SW, Park SM, Koo BK, et al. Efficacy of vitamin and antioxidant supplements in prevention of cardiovascular disease: systematic reviewed meta-analysis of randomized controlled trials. BMJ 2013; 346: f10.

[108] Konx EG. Ischemic heart disease mortality and dietary intake of calcium. Lancet 1973; 1: 1465-7.

[109] Enstrom JE, Kanim LE, Klein MA. Vitamin C intake and mortality amonga sample of the United State Population. Epidemiology 1992; 3: 194-202.

[110] Rimm EB, Stampfer MJ, Ascherio A, et al:: Vitamin E consumption and the risk of coronary heart disease in men. $N$ Engl J Med 1993, 328: 1450-56.

[111] Pandey DK, Shekelle R, Selwyn BJ, Tangney C, Stamler J. Dietary vitamin $\mathrm{C}$ and Bbeta carotene and risk of death in middle-aged men. The Western Electric Study. Am J Epidemiol 1995; 142: 1269-78.

[112] Gale CR, Martyn CN, Winter PD, Cooper C. Vitamin C and risk of death from strioke and coronary heart disease in a cohort of elderly people. BMJ 1995; 310: 1563-6.

[113] Carr AC, Frei B. Toward a new recommended dietary allowance for vitamin $\mathrm{C}$ based on antioxidant and health effects in humans. Am J Clin Nutr 1999; 69: 1086-107.

[114] NyyssÖnen K, Parviainen MT, Salonen R, Tuomilehto J, Salonen JT. Vitamin C deficiency and risk of myocardial infarction: prospective study of men from Eastern Finland. BMJ 1997; 314: 634-8.

[115] Khaw KT, Bingham S, Welch A, Luben R, Wareham N, Oakes $\mathrm{S}$, et al. Relation between plasma ascorbic acid and mortality in men and women in EPIC Norfolk prospective study: a prospective population study. Lancet 2001; 357: 657-63.

[116] Waters DD, Alderman EL, Hsia J, Howard BV, Cobb FR, Rogers WJ, et al. Effects of hormonal replacement therapy and antioxidant vitamin supplements on coronary artherosclerosis in postmenopausal women: a randomized controlled trial. JAMA 2002; 288: 2432-40.

[117] Shenkin A. Micronutrients deficicency conditions: global health issues. Pub H Rev 2010; 32: 243-55.

[118] Jaxa-Chamiec T, Bednarz B, Drozdowska D, Gessek J, Gniot J, Janik K, et al. Antioxidant effects of combined vitamin S and $\mathrm{E}$ in acute myocardial infarction. The randomized, double blind, placebo controlled, multicenter pilot, Myocardial infarction and vitamins (MIVIT) trial. Kardiol. Pol 2005; 62 (4): $344-50$.

[119] Frei B. On the role of vitamin C and other antioxidants in atherogenesis and vascular dysfunction. Proc. Soc. Exp Biol. Med 1999; 222 (3): 196-204.

[120] Huang A, Vita JA, Venema RC, Keaney JF. Ascorbic acid enhances endothelial nitricoxide synthase activity by increasing intracellular tetrahydrobiopterin. J Biol Chem 2000; 275 (23): 17399-406.

[121] Mozos I and Marginean O. Links between vitamin D deficiency and cardiovascular disease. BioMed Res Int 2015 (2015); $1099275: \quad 12 . \quad 101$ //dx.doi.org/10.1155/2015/2015/109275.

[122] Holick MF. Sunlight and vitamin D for bone health and prevention of autoimmune diseases, cancers, and cardiovascular disease. Am J. Clin. Nutr 2004; 80 (6): 1678s88 s.

[123] Giovannucci E, Liu Y, Hollis BW, Rimm EB. 25-Hydroxy vitamin $\mathrm{D}$ and risk of myocardial infarction in men: a prospective study. Arch Inter Med 2008; 168 (11): 1174-80.

[124] Atabek ME, Eklioglu BS, Akyurek N and Alp H. Association between vitamin D level and cardiovascular risk in obese children and adolescents. J. Pedeiatr Endocrinol Metab 2014; 27 (7-8): 661-6.

[125] Holick MF, Binkley NC, Bischoff-ferrari HA, Gordon CM, Hanley DA, Heaney RP et al., Evaluation, treatment, and prevention of vitamin D deficiency: an Endocrine Society clinical practice guideline. J Clin Endocrinol Metab 2011; 96 (7): 1911-30.

[126] Muscogiuri G, Sorice GP, Ajjan R, Mezza T, Pilz S, Prioletta A, Scragg R, Volpe SL, Witham MD, Giaccari A. Can vitamin $\mathrm{D}$ deficiency cause diabetes and cardiovascular disease? Present evidence and future perspectives. Nutr. Metab Cardiovasc Dis 2012; 22 (2): 81-7. 
[127] Pilz S, März W, Wellnitz B, Seelhorst U, Fahrleiter-Pammer A, Dimai HP, et al. Association of vitamin D deficiency with heart failure and sudden cardiac death in a large crosssectional study of patients referred for coronary angiography. J Clin Endocrinol Metab 2008: 93: 3927-35.

[128] Marniemi J, Alanen E, Impivaara O, Seppanen R, Hakala P, Rajala $\mathrm{T}$, et al. Dietary and serum vitamins and minerals as predictors of myocardial infarction and stroke in elderly subjects. Nutr Metab Cardiovasc Dis 2005; 15: 188-97.

[129] Xiang W, Kong J, Chen S, Cao LP, Qiao G, Zheng W, et al. cardiac hypertrophy in vitamin $\mathrm{D}$ receptor knock out mice: role of the systemic and cardiac rennin - angiotensin systems. Am J Physiol Endocrinol Metab 2005; 288: E125-E132.

[130] Kendrick J, Targher G, Smits G, and Chonchol M. 25Hydroxy vitamin D deficiency is independently associated with cardiovascular disease in the third national health and nutrition examination survey. Atherosclerosis 2009; 205 (1): 255-60.

[131] Bolland MJ, Bacon CJ, Home AM, Mason BH, Ames RW, Wang TK, et al. Vitamin D insufficiency and health outcomes over 5-1 in older women. AM J Clin Nutr 2010; 91 (1): 82-89.

[132] Hsia J, Heiss G, Ren H, Allison M, Dolan NC, Greenland P, Heckbert SR, Johnson HC, Manson JE, Sidney S, Trevisan M; Women's Health Initiative Investigators. Calcium/vitamin D supplementation and cardiovascular events. Circulation 2007: 115 (7); 846-54.

[133] Trivedic DP, Doll R, Khaw KT. Effect of four monthly oral vitamin $\mathrm{D}_{3}$ (cholecalciferal) supplementation on fractures and mortality in men and women living in the community: randomized double blind controlled trial. BMJ 2003; 326 (7387): 469.

[134] Michos ED, Blumenthal RS. Vitamin D supplementation and cardiovascular disease risk. Circulation 2007; 115: 827-8.

[135] Zittermann A, Dembinski J, Stehle P. Low vitamin D status is associated with lo cord blood levels of the immune suppressive cytokine interleukin-10. Pediatr Allergy Immunol 2004; 15 (3): 242-6.

[136] Judd SE, Tangpricha V. Vitamin D deficiency and risk for cardiovascular disease. Am J Med Sc. 2009: 338 (1), 40-4.

[137] Vieth R, Bischoff-Ferrari H, Boucher BJ, Dawson-Hughes B, Garland CF, Heaney RP, et al. The urgent need to recommend an intake of vitamin D that is effective. Am J Clin Nutr 2007; 85 (3): $649-50$.

[138] Holick MF, Chen TC. Vitamin D deficiency: a worldwide problem with health consequences. Am J Clin Nutr 2008; 87 (4): $1080 \mathrm{~S}-6 \mathrm{~S}$.

[139] Vieth R. Vitamin D supplementation 25-hydroxy vitamin D concentrations and safety. Am J Clin Nutr 1999; 69 (5): 84256 .

[140] Wortsman J, Matsuoka LY, Chen TC, Lu Z, Holick MF. Decreased bioavailability of vitamin D in obesity. AM J Clin Nutr 2000; 72 (3): 690-3.

[141] Hirani V, Tull K, Ali A, Mindell J. Urgent action needed to improve vitamin D status among older people in England: Age Aging 2010; 39 (4): 62-8.

[142] Schlaifer JD, Mancini GB, O’Neill BJ, Pitt B, Haber HE,
Pepine CJ. Influence of smoking status on angiotensinconverting enzyme inhibition-related improvement in coronary endothelial function. TREND investigators. Trial on Reversing Endothelial Dysfunction. Cradiovasc Drugs Ther 1999: 13; 201-9.

[143] Lausen JB, Rajagopalan S, Galis Z, Terpey M, Freeman BA, Harrison DG. Role of superoxide in angiotension ll-induced but not catecholamine-induced hypertension. Circulation 1997; 95: 588-93.

[144] Teng M, Wolf M, Ofsthun MN, Lazarus JM, Herman MA, Camargo CA, Thadhani R. Activated injectable vitamin D and hemodialysis survival: a historical cohort study. J Am Soc Nephrol 2005; 16 (4): 1115-25.

[145] Feki M, Souissi M, Mokhtar E, Hsairi M, Kaabachi N, Antebi $\mathrm{H}$, Alcindor LG, Mechmeche R, Mebazaa A. Vitamin E and Coronary Heart Disease in Tunisians. Clin Chem 2000; 46 (9): 1401-5.

[146] Sklowdska M, Wasovicz W, Gromadzinska J, Miroslaw W, Strzelczy KM, Malzuk J et al. Selenium and vitamin E concentration in plasma and erythrocytes of angina pectoris patients. Trace Elem Med 1993; 8: 113-7.

[147] Regnstrom J, Nilsson J, Modeus P, Strom K, Bavenhouhu P, Tornvall $\mathrm{P}$ Hamsten A. An inverse relation between the concentration of low density lipoproteins vitamin $\mathrm{E}$ and severity of coronary artery diseases. AM J. Clin Nurt 1996; 63: $377-85$.

[148] Stampfer MJ, Hennekens CH, Manson JE, Colditz GA, Rosner B, Willet WC. Vitamin E consumption and the risk of coronary disease in women N. Engl J Med 1993; 328: 1444-9.

[149] Kushi LH, Fee RM, Sellers TA, Zheng W, Folsom AR. Intake of vitamin $\mathrm{A}, \mathrm{C}$, and $\mathrm{E}$ and postmenopausal breast cancer: the Lowa womens' Health Study. Am J Epidemiol 1996; 144: 165-74.

[150] Meyer FI, Bairati and GR Dagenais. Lower ischemic heart disease incidence and mortality among vitamin supplement users. Can J Cardiol 1996; 12: 930-4.

[151] Gey, KF, Puska. Plasma vitamins E and A inversely correlated to mortality from ischemic heart disease in cross-cultural epidemiology. Ann N Y Acad Sci 1989; 570: 268-82.

[152] Riemersma RA, Wood DA, Macintyre CC, Elton RA, Gey KF, Oliver MF. Low plasma vitamins $\mathrm{E}$ and $\mathrm{C}$ : increased risk of angina in Scottish men. Ann. N. Y. Acad. Sci. 1989; 570: 291-5.

[153] Riemersma RA, Wood DA, McIntyre CAA, Elton RA, Gey $\mathrm{KF}$, Oliver MF. Risk of angina pectoris and plasma concentrations of vitamins $\mathrm{A}, \mathrm{C}$ and $\mathrm{E}$ and carotene. Lancet 1991; 337: $1-5$

[154] Losonczy KG, Harris TB, Havlik RJ. Vitamin E and vitamin C supplement use and risk of all-cause and coronary heart disease mortality in older persons: the Established populations for Epidemiologic studies of the Elderly. Am J. Clin Nurt 1996; 64: 190-6

[155] Klipstein-Grobusch K, Geleijnse JM, den Breeijen JH, Boeing H, Hofman A, Grobbee DE, Witteman JC. Dietary antioxidants and risk of myocardial infarction in the elderly: the Rotterdam study. Am J. Clin Nutr 1999; 69: 261-6.

[156] The Gissi-Prevenzione Trial. Dietary supplementation with n3 polyunsaturated fatty acids and vitamin $\mathrm{E}$ after myocardial infarction: results of the GISSI. Lancet 1999; 354: 447-55. 
[157] Salonen T, Salonen R, Pentula I, Herranen J, Jauhiainen M, Kantola I et al. Serum fatty acids, apolipoproteins, selenium and vitamin antioxidants and risk of death from coronary artery diseases. AM J Cardiol 1985; 56: 226-31

[158] Kok FJ, de Bruijn AM, Vermeeren R, Hofman A, van Laar A, de Bruin $M$ et al. Serum selenium and vitamin antioxidants and cardiovascular mortality: a 9-year follow-up study in the Netherlands. AM J Clin Nutr 1987: 45; 462-8.

[159] Blot WJ, Li JY, Taylor PR, Guo W, Dawsey S, Wang GQ, et al. Nutrition intervention trail in Lixian, China: supplementation with specific vitamin/mineral combinations, cancer incipience, and diseases specific mortality in the general population. J Natl Cancer Inst 1993: 85; 1483-91.

[160] Stephens NG, Parsous A, Schofiels PM, Kelly F, Cheeseman $\mathrm{K}$, Mitchinson MJ. Randomized controlled trail of vitamin $\mathrm{E}$ and coronary disease: the Cambridge Heart Antioxidant Study (CHAOS). Lancert 1996; 347: 781-6.

[161] The Heart Outcomes Prevention Evaluation Study Investigators (HOPES). Vitamin E supplementation and cardiovascular events in high-risk patients. $\mathrm{N}$ Engl $\mathrm{J}$ Med 2000; 342: 154-60.

[162] Pryor WA 2000. Vitamin E and heart diseases: Basic Science to clinical intervention trials. Fre Radic Biol Med 28: 141-64.

[163] Witztum J. The oxidation hypothesis of atherosclerosis. Lancet 1994; 344: 793-95.

[164] Steinberg D, Witztum JL. Is the oxidative modification hypothesis relevant to human atherosclerosis? Do the antioxidant trials conducted to date refute the hypothesis? Circulation 2002; 105 (17): 2107-11.

[165] Klein H, Pich S, Lindert S, Nebendahl K, Niedmann P, Kreuzer $\mathrm{H}$. Combined treatment with vitamin $\mathrm{E}$ and $\mathrm{C}$ in experimental Nyocardial infarction in pigs. American Heart Journal. 1989; 188 (4): 667-3.

[166] Freedman JE, Farhat JH, Loscalzo J, Keaney JF. Alphatocopherol inhibits aggregation of human platelets by a protein Kinase C-dependent mechanism. Circulation 1996; 94: 2434-40.

[167] Rota S, McWilliam NA, Baglin TP, Byrne CD. Atherosgenic lipoprotein support assembly of the prothrombinase complex and thrombin generation: modulation by oxidation and vitamin E. Blood 1998; 91 (2): 508-15.

[168] Wutzen J, Rozycka Z. Electron microscopic lesions of the myocardium of rats fed a low-magnesium diet. Pol Med Sci Hist Bull 1975: 15 (4): 407-14.

[169] Whang R. Clinical disorders of magnesium metabolism. Compr Ther 1997; 23: 168-73

[170] Reddy V, Sivakumar B. Magnesium dependent vitamin-Dresistant rickets. Lancet 1974; 1 (7864): 963-65.

[171] Rude RK, Adams JS, Ryzen E, Endres DB, Niimi H, Horst RL, Haddad JG Jr., Singer FR. Low serum concentrations of 1,25-dihydroxy vitamin $\mathrm{D}$ in human magnesium deficiency. $\mathrm{J}$ Clin Endocrinol Metab 1985; 61 (5): 933-40.
[172] Fuss M, Bergmann P, Bergans A, Bagon J, Cogan E, Pepersack T, Van Gossum M, Corvilain J. Correction of low circulating levels of 1, 25-duhydroxy vitamin $\mathrm{D}$ by 25 hydroxy vitamin D during reversal of hypo-magnesaemia. Clin Endocrinol (Oxf) 1989; 31 (1): 31-8.

[173] Rosanoff A, Dai Qi, Shapses SA. Essential nutrient interactions: Does low or suboptimal magnesium interact with vitamin D and/or calcium status? Advan Nutr 2016; 7 (1): 2543.

[174] Deng X, Song Y, Manson JE, Signorello LB, Zhang SM, Shrubsole MJ, Ness RM, Seidner DL, Dai Q. Magnesium, vitamin D status and mortality: results from US National Helath and Nutrition Examination Survey (NHANES) 2001 to 2006 and NHANES 111. BMC Med 2013; 11: 187.

[175] Rubin H. Central roles of $\mathrm{Mg}^{2+}$ and Mg ATP2 in the regulation of protein synthesis and cell proliferation: significance for neoplastic transformation. Adv Cancer Res. 2005; 93: 1-58.

[176] Wu F, Altura BT, Gao J, Barbour RL, Altura BM. Ferrylmyoglobin formation induced by acute magnesium deficiency in perfused rat heart causes cardiac failure. Biochim Biophys Acta- Mol Basis Dis 1994; 1225 (2): 158-64.

[177] Buettner GR. The pecking order of free radicals and antioxidants: lipid peroxidation, $\alpha$-Tocopherol, and ascorbate. Arch Biochem Biophy 1993; 200 (2): 535-43.

[178] Palozza P, Krinsky NI. Beta-carotene and alpha-tocopherol are synergistic antioxidants. Arch Biochem Biophys 1992; 297: 184-7.

[179] Packer JE, Slater TF, Wilson RL. Direct observation of a free radical interaction between vitamin $\mathrm{E}$ and vitamin $\mathrm{C}$. Nature 1979; 737-38.

[180] Leung H-W, Vang MJ, Mavis RD. The co-operative interaction between vitamin $\mathrm{E}$ and vitamin $\mathrm{C}$ in suppression of peroxidation of membrane phospholipids. Biochem Biophys Acta 1981; 664: 266-72.

[181] Singh RB, Niaz MA, Rastogi SS, Rastogi S. Usefulness of antioxidant vitamins in suspected acute myacardiac infarction (The Indian Experiment of Infarct Survival-3). Am J Cardiol 1996; 77 (2): 232-6.

[182] Witte KK, Clark AI, Cleland JGF. Chronic heart failure and micronutrients. J Am Coll Cardiol 2001; 37 (7): 1765-74.

[183] Miller KB, Caton JS, Schafer DM, Smith DJ, Finley JW. High dietary manganese lowers heart magnesium in pigs fed a lowmagnesium diet. J Nutr 2000; 130: 2032-5.

[184] Osredkar J, Susuatr N. Copper and Zinc, biological role and significant of copper/ zinc imbalance. J Clinic Toxicol 2011, S:3 http://dx.doi.org/10.4172/2161-0495.S3-001

[185] Reunaen A, Knekt P, Marniem J, Makt J, Maatela J, Aromaa A. serum calcium, magnesium, copper and zinc and risk of cardiovascular death. Eur J Clin Nutr 1996; 50 (7): 431-7. 